\title{
Idealized Modeling of the Atmospheric Boundary Layer Response to SST Forcing in the Western Indian Ocean
}

\author{
ADAM V. RYdBECK AND TOMMY G. JENSEN \\ U.S. Naval Research Laboratory, Stennis Space Center, Mississippi \\ MATTHEW R. IGEL \\ Department of Land, Air and Water Resources, University of California, Davis, Davis, California
}

(Manuscript received 9 October 2018, in final form 18 April 2019)

\begin{abstract}
The atmospheric response to sea surface temperature (SST) variations forced by oceanic downwelling equatorial Rossby waves is investigated using an idealized convection-resolving model. Downwelling equatorial Rossby waves sharpen SST gradients in the western Indian Ocean. Changes in SST cause the atmosphere to hydrostatically adjust, subsequently modulating the low-level wind field. In an idealized cloud model, surface wind speeds, surface moisture fluxes, and low-level precipitable water maximize near regions of strongest SST gradients, not necessarily in regions of warmest SST. Simulations utilizing the steepened SST gradient representative of periods with oceanic downwelling equatorial Rossby waves show enhanced patterns of surface convergence and precipitation that are linked to a strengthened zonally overturning circulation. During these conditions, convection is highly organized, clustering near the maximum SST gradient and ascending branch of the SST-induced overturning circulation. When the SST gradient is reduced, as occurs during periods of weak or absent oceanic equatorial Rossby waves, convection is much less organized and total rainfall is decreased. This demonstrates the previously observed upscale organization of convection and rainfall associated with oceanic downwelling equatorial Rossby waves in the western Indian Ocean. These results suggest that the enhancement of surface fluxes that results from a steepening of the SST gradient is the leading mechanism by which oceanic equatorial Rossby waves prime the atmospheric boundary layer for rapid convective development.
\end{abstract}

\section{Background}

The horizontal distribution of sea surface temperature (SST) modulates and sometimes determines tropical convective development and organization. Malkus (1957) was among the first to observe and analyze the clustering of tropical cumulus clouds over strong SST gradients. She proposed that these gradients assist the initiation and organization of cumulus cloud populations. Observations inspiring this hypothesis were obtained during an expedition to the Caribbean using a two-engine amphibious patrol bomber, PBY-6A, provided by the Office of Naval Research. The plane was outfitted with a downward-facing radiometer and a motion picture camera that captured clouds passing overhead as the plane flew at $1000 \mathrm{ft}(305 \mathrm{~m})$. During the expedition, clouds

Corresponding author: Adam V. Rydbeck, adam.rydbeck@ nrlssc.navy.mil were most frequently observed near oceanic warm patches in regions where the SST gradient was steepest, often between 0.01 and $0.03 \mathrm{~K} \mathrm{~km}^{-1}$. After performing tedious hand analyses of the results, Malkus (1957) hypothesized that the oceanic hot spots acted as "equivalent mountains," which generated sea-breeze-like circulations wherein the magnitude of the wind response was controlled by the horizontal SST change. She theorized that solenoidal circulations driven by the SST gradients were responsible for moisture variations at low levels. Contrastingly, cumulus cloud clusters were absent in observations over regions of uniform SST.

Building on the groundwork of Malkus (1957), Li and Carbone (2012) observed that $\sim 75 \%$ of rainfall events in the tropical western Pacific Ocean initiated in close proximity to mesoscale SST gradients. The onset of rainfall preferentially occurred adjacent to local warm patches, in close proximity to minima of the negative Laplacian of SST. Using formulas derived to estimate 
the magnitude of convergence induced by the SST field, the forcing by mesoscale SST gradients was an order of magnitude larger than the environmental background convergence, thus driving the regional excitation of cumulus clouds. Li and Carbone (2012) suggested that this mechanism is likely most effective when the atmosphere is susceptible to weak forcing and no large-scale subsidence in the overlying free troposphere is occurring.

At much larger scales, Lindzen and Nigam (1987) used a simple model to recreate many of the climatological features of the Pacific intertropical convergence zone and concluded that the distribution of SST significantly contributed to the magnitude and location of low-level convergence. This was in addition to contributions by the SST maxima and associated moist static energy maxima (Neelin et al. 1987). Grabowski et al. (2000) analyzed an ensemble of idealized two-dimensional cloudresolving simulations with a sinusoidal SST pattern ranging from $24^{\circ} \mathrm{C}$ on the edges to $28^{\circ} \mathrm{C}$ at the model center. After several weeks, the simulations reached equilibrium, and were characterized by shallow $(<1 \mathrm{~km})$ inflow toward the warmest SST at the center of the domain. The inflow pattern initially driven by the SST distribution resulted in precipitation maxima near the domain center, further demonstrating the role of SST gradients in determining large-scale climatological low-level convergence and precipitation patterns. The present investigation is an extension of mechanisms examined in these previous works with particular emphasis on the role of the SST distribution to intraseasonal convective onset.

Of particular relevance for this study, SST patterns are hypothesized to modulate boundary layer convergence during the initiation and propagation of the intraseasonal oscillation (ISO) (Madden and Julian 1971; Hsu and Li 2012; Carbone and Li 2015; Rydbeck and Jensen 2017). Hsu and Li (2012) observed a moisture increase below $700 \mathrm{hPa}$ to the east of ISO convection that is largely driven by horizontal moisture convergence. Using a simplified boundary layer model, $75 \%-90 \%$ of the boundary layer convergence to the east of ISO convection was forced by the large-scale atmospheric wave response to convective heating, and $10 \%-25 \%$ of the convergence resulted from SST-induced pressure gradients. Carbone and Li (2015) observed that SST forcing of boundary layer convergence led ISO convection by $\sim 10$ days in the Eastern Hemisphere. The observed correlations between ISO SST forcing and rainfall were particularly strong in the western Indian Ocean, suggesting a role for SST-forced boundary layer convergence in ISO initiation [see Figs. 9 and 11 of Carbone and $\mathrm{Li}(2015)]$.

Webber et al. (2010, 2012a,b) first documented the relationship between downwelling equatorial Rossby waves and ISO convective onset, and their work inspired much of this investigation. Webber et al. (2010) suggested that surface latent heat flux anomalies manifest in response to warm SST anomalies associated with oceanic downwelling equatorial Rossby waves and are responsible for ISO convective onset. However, using reanalysis data, Rydbeck and Jensen (2017) did not observe notable increases in surface fluxes prior to ISO convective onset associated with downwelling waves. Instead, Rydbeck and Jensen (2017) suggested that tenacious warming of the sea surface resulting from horizontal advection by oceanic equatorial Rossby wave currents and a concomitant steepening of the SST gradient acted as a large-scale source of boundary layer upward motion (e.g., Lindzen and Nigam 1987; Back and Bretherton 2009) and moisture convergence. They estimated that SST forcing accounted for up to $45 \%$ of the intraseasonal boundary layer convergence, and hypothesized that this lead to increased boundary layer moisture convergence, upward vertical motion, and ISO convective onset.

The SST forcing observed in Rydbeck and Jensen (2017) is produced by oceanic downwelling equatorial Rossby waves. Equatorial Rossby waves are observed to propagate symmetrically about the equator along $4^{\circ} \mathrm{N}$ and $4^{\circ} \mathrm{S}$ at $\sim 1 \mathrm{~m} \mathrm{~s}^{-1}$ with strongest currents along the equator that span much of the central and western Indian Ocean [see Fig. 1 of Rydbeck et al. (2017)]. Horizontal advection by downwelling equatorial Rossby waves accounts for a majority of the intraseasonal SST warming $\left(+0.15^{\circ}\right.$ to $\left.+0.3^{\circ} \mathrm{C}\right)$ (Rydbeck et al. 2017). The sea surface warming associated with downwelling equatorial Rossby waves is remarkably unyielding, even when cooling by processes related to atmospheric convection, such as reduced incoming shortwave radiation and increased latent heat fluxes, are active. The persistent SST pattern during these periods of strong ocean dynamics is leveraged in model simulations described later wherein the SST is fixed in time.

The purpose of this study is to gain insight into the relative contributions made by surface latent heat flux and boundary layer convergence variations that are driven by oceanic downwelling equatorial Rossby waves prior to ISO convective onset. These two mechanisms for destabilizing the atmosphere toward enhanced convection are investigated using an atmospheric cloud system-resolving model. The atmospheric boundary layer divergence budget used to analyze model simulations is introduced in section 2 . In section 3 , we describe the model setup and ensemble of simulations performed. Section 4 examines the boundary layer response and convective organization in simulations 
with and without equatorial Rossby waves. The roles of SST-forced convergence and surface fluxes in the boundary layer are also analyzed. Discussion of modeling results in the context of recent ISO observations are provided in section 5 . Conclusions regarding the modification of the atmospheric boundary layer by SST gradients associated with equatorial Rossby waves are presented in section 6 .

\section{Atmospheric boundary layer divergence equation}

To determine the processes responsible for varying patterns of low-level convergence, we utilize the atmospheric boundary layer horizontal divergence budget. The vertically integrated budget in Cartesian coordinates may be expressed as

$$
\left[\begin{array}{c}
\partial \delta \\
\partial t
\end{array}\right]=\overbrace{-[(\mathbf{U} \cdot \nabla) \delta]}^{\mathrm{i}}-\overbrace{\left[\delta^{2}\right]}^{\mathrm{ii}}+\overbrace{\left[2\left(\frac{\partial u}{\partial x} \frac{\partial v}{\partial y}-\frac{\partial v}{\partial x} \frac{\partial u}{\partial y}\right)\right]}^{\mathrm{iii}}-\overbrace{\left[\frac{\partial \omega}{\partial x} \frac{\partial u}{\partial p}-\frac{\partial \omega}{\partial y} \frac{\partial v}{\partial p}\right]}^{\mathrm{iv}}+\overbrace{[f \zeta]}^{\mathrm{v}}-\overbrace{[\beta u]}^{\mathrm{vi}}-\overbrace{\left[\nabla_{x, y}^{2} \Phi\right]}^{\mathrm{vii}}+\overbrace{\text { Residual }}^{\text {viii }}
$$

in pressure coordinates, where square brackets indicate vertical integrals, and

$$
\begin{aligned}
{\left[\frac{\partial \delta}{\partial t}\right]=} & \overbrace{-[(\mathbf{U} \cdot \nabla) \delta]}^{\mathrm{i}}-\overbrace{\left[\delta^{2}\right]}^{\mathrm{ii}}+\overbrace{\left[2\left(\frac{\partial u}{\partial x} \frac{\partial v}{\partial y}-\frac{\partial v}{\partial x} \frac{\partial u}{\partial y}\right)\right]}^{\mathrm{iii}}-\overbrace{\left[\frac{\partial w}{\partial x} \frac{\partial u}{\partial z}-\frac{\partial w}{\partial y} \frac{\partial v}{\partial z}\right]}^{\mathrm{iv}} \\
& +\overbrace{[f \zeta]}^{\mathrm{v}}-\overbrace{[\beta u]}^{\mathrm{vi}}-\overbrace{\left[\nabla_{x, y} \cdot\left(\rho^{-1} \nabla_{x, y} p\right)\right]}^{\mathrm{vii}}+\overbrace{\text { Residual }}^{\text {viii }}
\end{aligned}
$$

in height coordinates, where $\delta=\nabla_{x, y} \cdot \mathbf{U}$. Equation (2) is used to perform a detailed analysis of the boundary layer divergence tendencies in Cloud Model 1 (CM1) simulations in section 4 but are discussed here as a preamble.

Equations (1) and (2) are the divergence tendency equations for pressure and height coordinates, respectively (Sherman 1952; Stevens 1979). The term on the left-hand side is the divergence tendency. Schematics of the general terms on the right-hand side of Eq. (1), not including advection and the residual, are shown in Fig. 1. Label " $C$ " indicates regions of negative divergence tendency, also referred to as the convergence tendency. Term $\mathrm{i}$ on the right-hand side is the advection of divergence. Term ii is the effect of divergence on divergence. Because term ii is always negative (i.e., the negative of a squared term), it is the tendency of the atmosphere toward convergence. Term iii includes the Jacobian of the horizontal winds and represents the divergence tendency owing to deformation of the horizontal flow. Term iv is the divergence tendency that results from differential vertical advection of horizontal winds. This is sometimes referred to as the tilting term (Stevens 1979). Term $v$ is the divergence tendency that results from the Coriolis force acting on the relative vorticity. In the Northern Hemisphere, the Coriolis force acting on anticyclonic (cyclonic) relative vorticity results in a convergence (divergence) tendency. Term vi is the divergence tendency resulting from latitudinal variations of the Coriolis force acting on the zonal wind. Term vii is the divergence tendency that results from the Laplacian of the geopotential or pressure field. This is the only term that directly relates to the thermodynamic properties of the atmosphere. All other terms are derived from the wind field, such that, in an initially motionless atmosphere, divergence is slave to variations in atmospheric thickness. The shape of the boundary layer geopotential height field is determined by several factors including the lower boundary condition (i.e., sea surface temperature), diabatic heating, and other free-tropospheric effects such as atmospheric equatorial waves. To tease apart the thermodynamic contributions to the forcing of boundary layer convergence, particularly the contributions by SST, during this period, a set of idealized modeling simulations, discussed in section 3 , are performed. The residual, term viii, includes the effects of viscous forces, horizontal and vertical mixing, and any errors in the calculations of budget terms.

\section{Model}

An idealized atmospheric model is used to understand the response of the atmospheric boundary layer to spatial variations of SST associated with oceanic downwelling equatorial Rossby waves, particularly as they relate to the organization of boundary layer moisture 


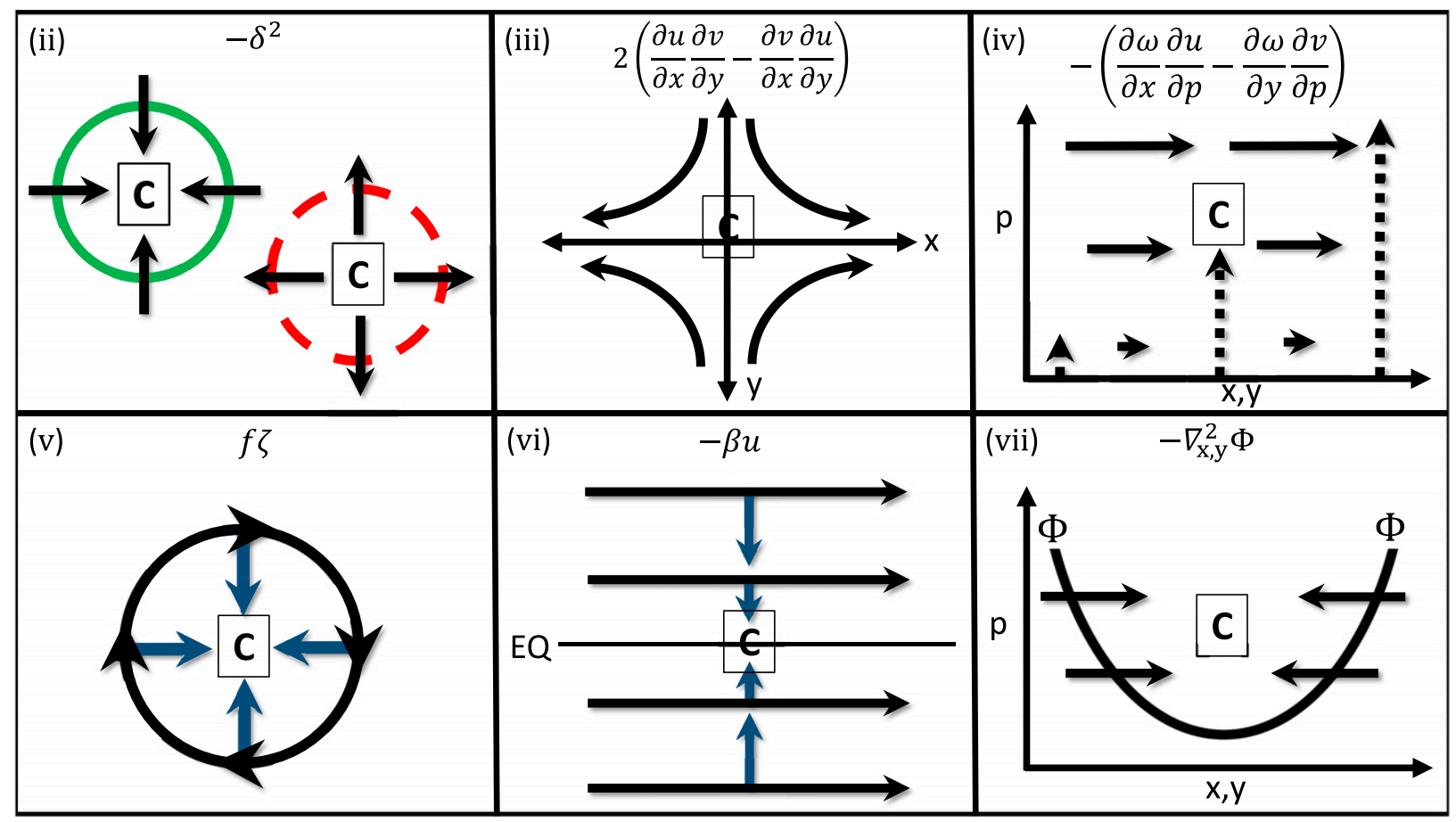

FIG. 1. The schematic of terms in the divergence budget equation [Eq. (1)]. "C" indicates regions with a convergence tendency (negative divergence tendency). See text for description of terms.

and atmospheric convection. Resolving processes that communicate energy from the ocean surface vertically through the atmosphere are of critical importance in adequately resolving the role of downwelling equatorial Rossby waves to convective growth in the western Indian Ocean. With this in mind, CM1, release 18.3 (Bryan and Fritsch 2002), is used. CM1 is a nonlinear, nonhydrostatic, threedimensional cloud-resolving model that is useful for idealized simulations of atmospheric processes. CM1 has proven useful for investigating intraseasonal variability in the tropical Indian Ocean, including the transition from convectively suppressed to active phases of the ISO (Ruppert and Johnson 2016; Ruppert 2016).

\section{a. Framework}

Because of the large-scale phenomena being investigated, specifically air-sea interactions involving oceanic equatorial Rossby waves with zonal wavelengths on the order of megameters $\left(\times 10^{3} \mathrm{~km} ; \mathrm{Mm}\right)$, the dimensions of the CM1 domain are necessarily large. We have run various simulation over two domains. Our standard domain is $2496 \mathrm{~km} \times 624 \mathrm{~km} \times 22 \mathrm{~km}$. Our secondary domain is twice as long but half as wide at $4992 \mathrm{~km} \times 312 \mathrm{~km} \times 22 \mathrm{~km}$. We call this domain the "narrow channel." The standard domain has doubly periodic boundaries while the narrow-channel domain has open zonal boundaries and periodic meridional boundaries. The lateral boundaries are doubly periodic in the first domain so that boundary interference does not detract from the development of solenoidal circulations in the atmospheric boundary layer. The second domain is double the zonal length of the first domain in order to distance the impacts of the open boundaries from the region of interest near the model center. The horizontal grid spacing is $2 \mathrm{~km}$, and the model has 99 vertical levels. The vertical grid is stretched for levels located between 2.4 and $15 \mathrm{~km}$ using the method of Wilhelmson and Chen (1982), with grid spacing of $60 \mathrm{~m}$ below $2.4 \mathrm{~km}$ and $500 \mathrm{~m}$ above $15 \mathrm{~km}$. The compressible, vertically implicit pressure solver (Klemp et al. 2007) is chosen. An adaptive time step ( $\sim 10 \mathrm{~s})$, fifth-order horizontal advection (Wicker and Skamarock 2002), upper-level Rayleigh damping above $18.2 \mathrm{~km}$, and no planetary vorticity (or, rather, an $f$ plane centered on the equator) are used. The model is initialized with random temperature perturbations smaller than $0.1 \mathrm{~K}$ in magnitude.

The focus of this study is boundary layer processes. The model is set up to resolve explicitly the planetary boundary layer with $60-\mathrm{m}$ vertical grid spacing. Subgrid-scale turbulent kinetic energy is predicted using the methods of Deardorff (1980), similar to that used for 


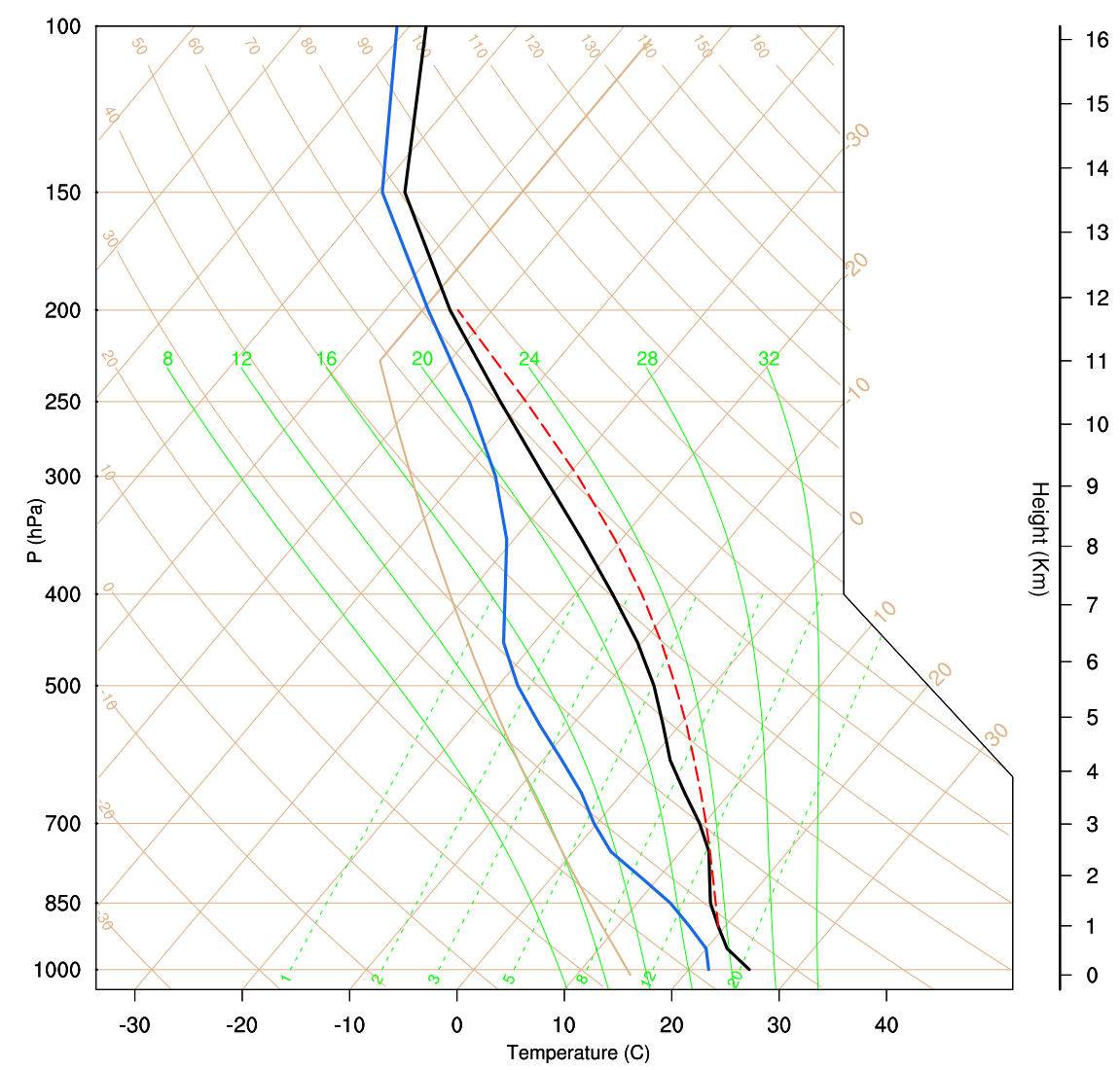

FIG. 2. The composite thermodynamic vertical profile used to initiate all model simulations. Moisture and temperature are averaged over $6^{\circ} \mathrm{S}-6^{\circ} \mathrm{N}, 58^{\circ}-65^{\circ} \mathrm{E}$ and from lags -10 to 0 days. Background winds are set to 0 . The moist adiabatic lapse rate (green), dry adiabatic lapse rate (brown), moisture (green), environmental temperature profile (black), environmental moisture profile (blue), and parcel trajectory (dashed red) are shown.

large-eddy simulations (LESs). Convection is also simulated explicitly with microphysics calculated using the double-moment Morrison scheme (Morrison et al. 2005, 2009). Surface fluxes of heat and moisture are calculated using bulk formulation with specified surface exchange coefficients. The heat and moisture exchange coefficients derived from ship observations during the DYNAMO field campaign (Moum et al. 2014) and used in previous CM1 studies of the ISO (Ruppert and Johnson 2016; Ruppert 2016) are selected. They are $1.66 \times 10^{-3}$ and $1.74 \times 10^{-3}$, respectively.

Radiative tendencies are calculated every 5 min using the NASA Goddard longwave and shortwave radiation schemes with the local time held fixed for the location of $0^{\circ}, 60^{\circ} \mathrm{E}$ such that there is no diurnal cycle of radiation. While previous studies have shown important contributions of moisture buildup in the boundary layer and free troposphere, owing partly to diurnal variability of cumulus clouds rectifying onto longer time scales (e.g., Ruppert and Johnson 2016), to the onset of tropical deep convection, we are focused on the contributions made by large-scale SST gradients. Accordingly, diurnal variations are suppressed such that signals from the SST gradient forcing feature more prominently. In total, there are 38548224 grid points on which the model operates that are divided over 52 processors. A 10-day simulation requires $\sim 10$ clock days to complete. Simulations without moisture and radiation physics require $\sim 2.5$ clock days and are briefly mentioned in the analysis.

\section{b. Simulations}

Initial atmospheric conditions are prescribed uniformly across the model domain from a composite sounding. The sounding is obtained by averaging atmospheric thermodynamic variables from lags -10 to 0 days of the downwelling equatorial Rossby wave composite formulated in Rydbeck and Jensen (2017) and over the domain $6^{\circ} \mathrm{S}-$ $6^{\circ} \mathrm{N}, 58^{\circ}-65^{\circ} \mathrm{E}$. This corresponds to periods when suppressed intraseasonal convection transitions to active intraseasonal convection. Figure 2 shows the composite sounding used in all CM1 simulations. The atmosphere 
TABLE 1. Descriptions of CM1 10-day simulations performed and the leading differences among their setup.

\begin{tabular}{|c|c|c|c|}
\hline \multicolumn{2}{|c|}{ Doubly periodic domain $(2494 \mathrm{~km} \times 624 \mathrm{~km} \times 22 \mathrm{~km})$} & \multicolumn{2}{|c|}{ Narrow-channel domain $(4988 \mathrm{~km} \times 312 \mathrm{~km} \times 22 \mathrm{~km})$} \\
\hline Simulation & Attributes & Simulation & Attributes \\
\hline Control & $\begin{array}{l}\text { Sinusoidal SST distribution } \\
\text { Doubly periodic boundary } \\
\text { conditions } \\
\text { SST range: } 27.9^{\circ}-28.8^{\circ} \mathrm{C}\end{array}$ & $\begin{array}{l}\text { Control narrow } \\
\text { channel }\end{array}$ & $\begin{array}{l}\text { Hyperbolic tangent SST distribution } \\
\text { Meridionally periodic and zonally } \\
\text { open/radiative boundary conditions } \\
\text { SST range: } 27.4^{\circ}-29.0^{\circ} \mathrm{C}\end{array}$ \\
\hline Downwelling & $\begin{array}{l}\text { Sinusoidal SST distribution } \\
\text { Doubly periodic boundary } \\
\text { conditions } \\
\text { SST range: } 26.5^{\circ}-28.6^{\circ} \mathrm{C}\end{array}$ & $\begin{array}{l}\text { Downwelling } \\
\text { narrow channel }\end{array}$ & $\begin{array}{l}\text { Hyperbolic tangent SST distribution } \\
\text { Meridionally periodic and zonally } \\
\text { open/radiative boundary conditions } \\
\text { SST range: } 26.3^{\circ}-28.8^{\circ} \mathrm{C}\end{array}$ \\
\hline $\begin{array}{l}\text { Downwelling mean SST } \\
\text { withcontrol SST } \\
\text { gradient }\end{array}$ & $\begin{array}{l}\text { Sinusoidal SST distribution } \\
\text { Doubly periodic boundary } \\
\text { conditions } \\
\text { SST range: } 27.1^{\circ}-28.0^{\circ} \mathrm{C}\end{array}$ & & \\
\hline $\begin{array}{l}\text { Downwelling mean SST } \\
\text { withno SST gradient }\end{array}$ & $\begin{array}{l}\text { Homogeneous SST distribution } \\
\text { Doubly periodic boundary conditions } \\
\text { SST range: } 27.5^{\circ} \mathrm{C}\end{array}$ & & \\
\hline
\end{tabular}

is conditionally unstable with a narrow region of convective available potential energy (CAPE) that typifies the tropical warm pool $\left(840 \mathrm{~J} \mathrm{~kg}^{-1}\right.$ and $40 \mathrm{~mm}$ of precipitable water). The background horizontal and vertical wind profile is suppressed with no large-scale forcing or relaxation imposed; this allows us to focus on the effects of the SST gradient on the atmospheric boundary layer wind response.

Properties of the CM1 ensemble of simulations are provided in Table 1. Within the respective domains, the same model configuration is used, except for variations to the bottom boundary condition (i.e., SST). The bottom boundary conditions for CM1 are prescribed using SST composites from periods with and without oceanic equatorial Rossby waves, respectively. The downwelling simulations utilizes SST composites from NOAA OISST averaged from $6^{\circ} \mathrm{S}$ to $6^{\circ} \mathrm{N}$ and from 5 to 10 days after oceanic equatorial Rossby waves arrive in the western Indian Ocean. This corresponds to periods when the anomalous SST gradient magnitude is a maximum [see Fig. 11 of Rydbeck and Jensen (2017)]. Rydbeck et al. (2017) observed that the warm SST and enhanced SST gradient anomalies are largely driven by horizontal advection of mean SST by oceanic equatorial Rossby wave currents. Because ocean currents are responsible for maintaining the warm SST distribution, even against the cooling effects of atmospheric convection, the use of a fixed SST for the duration of the 10-day simulation is reasonable. A separate simulation is performed using SST composited for periods when oceanic equatorial Rossby wave activity is suppressed in the western Indian Ocean, referred to as the control simulation. For simplicity only zonal variations of SST are included in the bottom boundary conditions for the simulations. However, we note that meridional SST gradients have previously been suggested as having equal importance to the intraseasonal modulation of the atmospheric boundary layer (Rydbeck and Jensen 2017), such that the downwelling simulations likely underestimate the SST gradient effects.

The observed SST composites for the downwelling and control periods, along with their analytic representations in the model, are shown in Fig. 3. The scaling of Fig. 3 intentionally exaggerates the SST gradients for emphasis. The model SSTs closely follows the observed SST pattern on the western edge in the doubly periodic domain (Fig. 3a) but is zonally symmetric to avoid a jump along the periodic lateral boundaries. In the idealized modeling framework, the SST profile may be thought of as an "equivalent mountain," as suggested by Malkus (1957), and proven effective for examining "mock Walker circulations" (e.g., Bretherton et al. 2006; Bretherton and Sobel 2002; Grabowski et al. 2000; Kuang 2012). The narrowchannel model SST patterns closely follow the downwelling and control observational composites, except west of $50^{\circ} \mathrm{E}$ where model SSTs are smoothed for simplicity (Fig. 3b).

In observations, the SST gradients between $50^{\circ}$ and $65^{\circ} \mathrm{E}$ are $1.5^{\circ}$ and $0.8^{\circ} \mathrm{CMm}^{-1}$ for the downwelling and control composites, respectively. The SST gradient is almost doubled during periods of downwelling equatorial Rossby waves. Interestingly, the SST is slightly warmer during inactive equatorial Rossby wave periods versus downwelling equatorial Rossby wave periods. Periods of strong wind stress across the equatorial 

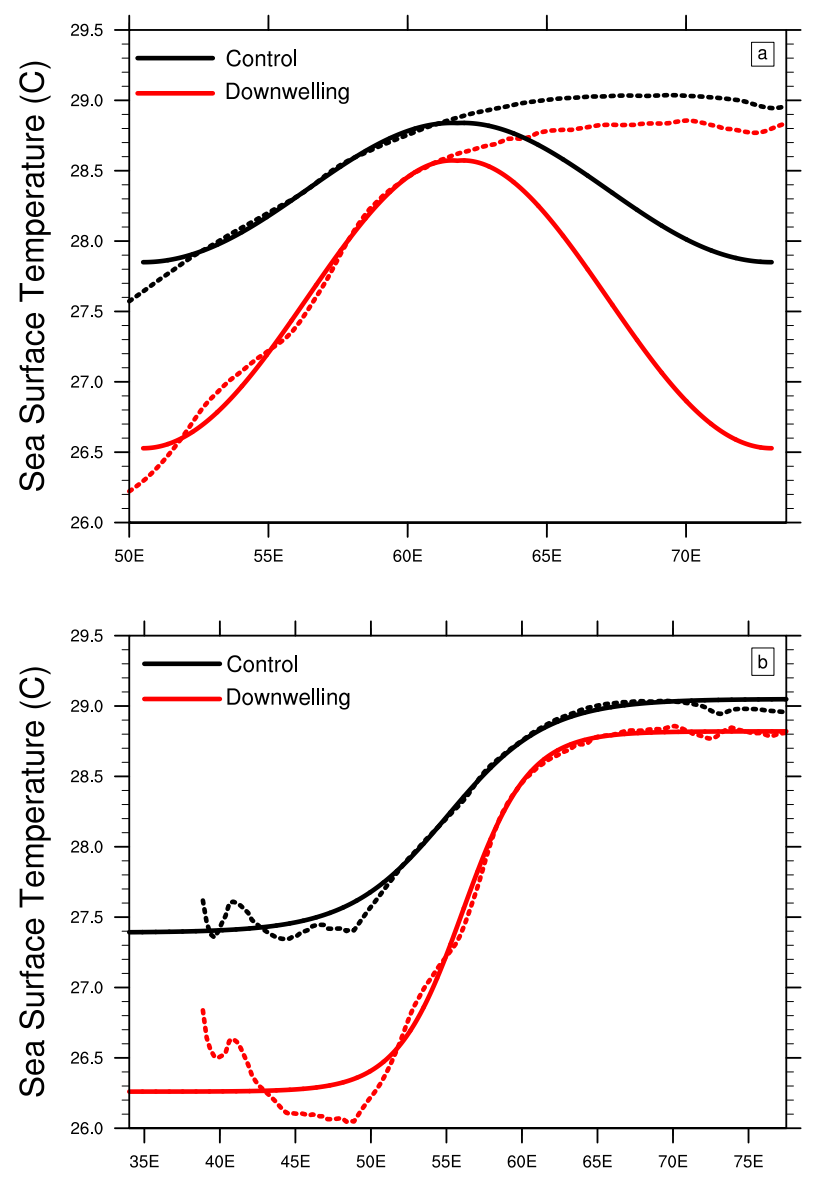

FIG. 3. The composite zonal NOAA OISST profiles averaged from $6^{\circ} \mathrm{S}$ to $6^{\circ} \mathrm{N}$ are shown for periods without equatorial Rossby waves (dashed black) and periods with downwelling equatorial Rossby waves (dashed red). The downwelling profile is averaged from lags 5 to 10 days of the equatorial Rossby wave index. Model SSTs are shown for the control (solid black) and downwelling (solid red) simulations in for the (a) doubly periodic and (b) narrowchannel domain.

Indian Ocean associated with westerly intraseasonal and intermonsoon surface winds precede downwelling equatorial Rossby waves and possibly explains the cooler SST (Rydbeck and Jensen 2017). These wind events are periods of strong mixing and cooling of the upper ocean that may not fully recover prior to the arrival of downwelling equatorial Rossby waves in the western Indian Ocean 75-90 days later (Moum et al. 2016).

In establishing the most suitable modeling framework, the use of periodic lateral boundary conditions became preferable to the use of an open radiative boundary and is the main focus of the analysis. The edge effects of open radiative boundaries are, on occasion, observed to disturb the flow within the regions of interest because of the short-lived development of deep convection along the warmest boundaries that subsequently radiated gravity waves toward the model interior (see Fig. 13). Even so, the open boundary simulation results are presented as additional support of the findings from the doubly periodic domain.

\section{Modeling results}

An ensemble of model simulations with differences in the distribution of SST in order to represent periods with and without oceanic downwelling equatorial Rossby waves, noted in their simulation descriptions as "downwelling" and "control," are analyzed. To identify differences in the overturning circulation driven by the SST profile between simulations, the evolution of the respective boundary layer winds and boundary layer tops are examined. Using the divergence budget discussed in section 2, processes responsible for the large-scale divergence tendency are quantified to determine the relative contribution made by the SST distribution. Differences in the magnitude of the large-scale circulation are shown to force dramatic shifts of convective organization between the downwelling and control simulations. Processes that regulate these convective behaviors are also investigated.

\section{a. Large-scale circulations}

Cross sections of daily and meridionally averaged vertical and zonal winds are shown for the downwelling (Fig. 4) and control (Fig. 5) simulations to illustrate the boundary layer response to tropical SST profiles with and without oceanic downwelling equatorial Rossby waves. On day 1 , boundary layer winds in the downwelling simulation are characterized by weak upward motion over the warmest SST with confluent zonal flow (Fig. 4a). The boundary layer height adjusts quickly and resembles the shape of the SST pattern, peaking at $625 \mathrm{~m}$ and descending to $185 \mathrm{~m}$ over the coolest SST. Boundary layer height is defined as the height at which the virtual potential temperature increases by more than $0.25 \mathrm{~K}$ from the virtual potential temperature at the lowest model level. Prior to diabatic heating from convection, convergence within the sea-breeze-like circulation is proportional to the negative of the Laplacian of SST. In the case of a sinusoidal SST distribution, the negative of the Laplacian of the SST takes the shape of the SST. From this, convergence is expected in regions where the concavity of the zonal SST profile is downward (sometimes referred to as a "bubbling up" of SST; Carbone and Li 2015). For these simulations, convergence forced by the SST field occurs inward of the SST inflection point at $625 \mathrm{~km}$ with maximum forcing at $0 \mathrm{~km}$. Boundary layer zonal wind magnitudes are greatest over the strongest SST gradients. On day 1 of the control simulation (Fig. 5a), the boundary layer height also mirrors the 

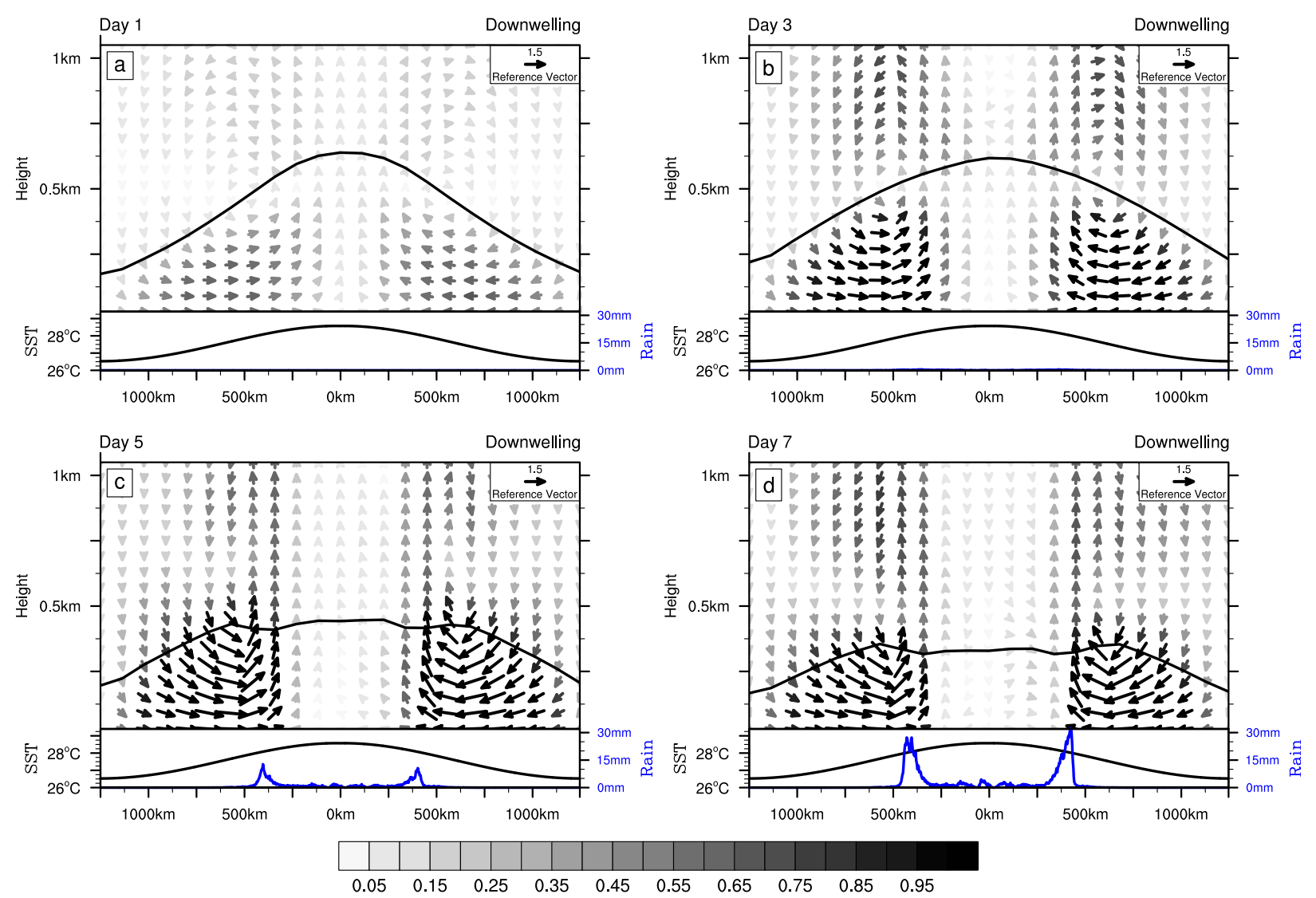

FIG. 4. Meridionally and daily averaged zonal $\left(\mathrm{m} \mathrm{s}^{-1}\right)$ and vertical $\left(\mathrm{cm} \mathrm{s}^{-1}\right)$ winds are shown for (a) day 1, (b) day 3, (c) day 5, and (d) day 7 of the downwelling simulation. Average boundary layer height is also shown for each day (solid black line). The SST profile used in the simulation is shown below each panel, as is the daily average rainfall. The reference vector is shown in the upper right of each panel.

shape of the SST profile and its maximum is slightly higher $(\sim 75 \mathrm{~m})$ than the downwelling simulation.

Differences are much greater in the region of cooler SSTs, where the control simulation boundary layer height is deeper by almost $500 \mathrm{~m}$. The flow structure present on day 1 is forced entirely by the SST, since cloud condensational heating and its feedback to the circulation is not yet present. Similar day 1 boundary layer responses are observed for simulations performed without moisture and shortwave/longwave radiation (not shown). On day 3 , the boundary layer maxima are located at approximately the same altitude, near $600 \mathrm{~m}$ (Figs. 4b and 5b) and generally agree with those observed during transitions from suppressed to active periods of the ISO during DYNAMO (Chen et al. 2016; Johnson and Ciesielski 2017). The circulations from day 1 have intensified in both simulations. On days 5 and 7 , rainfall increases, the boundary layer height shoals, and horizontal and vertical velocities intensify in both simulations (Figs. 4c, 4d, 5c, and 5d). Velocities are much stronger in the downwelling simulation and slightly shifted inward, toward the SST maximum, relative to the control simulation. For each day, the boundary layer overturning circulation is stronger in the downwelling simulation and is associated with enhanced low-level convergence patterns and enhanced rainfall.

The leading contributors to the evolution of the divergence field in the downwelling and control simulations are next examined using the vertically integrated divergence budget of Eq. (2). Figure 6 shows the divergence budget terms for the downwelling (Fig. 6a) and control (Fig. 6b) simulations, respectively. Terms are integrated from the surface to $270 \mathrm{~m}$ and averaged meridionally over the entire domain and zonally from 625 to $625 \mathrm{~km}$ to capture the region of low-level convergence forced by the SST. The tendency, redistribution (term i + term ii + term iii + term iv), pressure (term vii), residual (term viii), and tendency from SST [see Eq. (3)] terms are shown. Because model simulations are performed with no planetary vorticity, the vorticity terms (terms $\mathrm{v}$ and vi) are zero and not shown.

The boundary layer convergence (long-dashed black line) is $\sim 40 \%$ greater in the downwelling simulation 

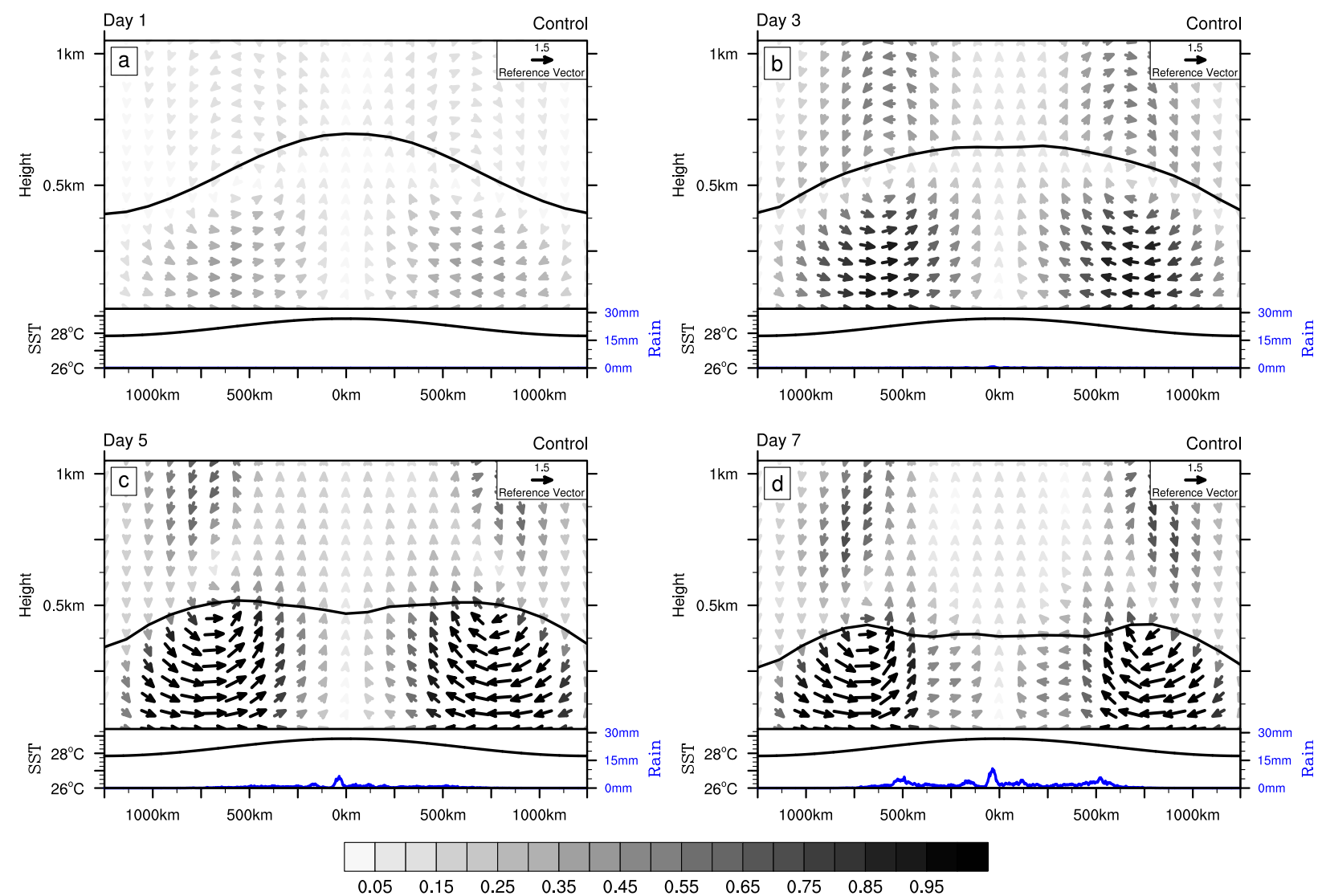

FIG. 5. Meridionally and daily averaged zonal $\left(\mathrm{m} \mathrm{s}^{-1}\right)$ and vertical $\left(\mathrm{cm} \mathrm{s}^{-1}\right)$ winds are shown for (a) day 1, (b) day 3, (c) day 5, and (d) day 7 of the control simulation. Average boundary layer height is also shown for each day (solid black line). The SST profile used in the simulation is shown below each panel, as is the daily average rainfall. The reference vector is shown in the upper right of each panel.

than the control simulation over the first 5 days (Fig. 6). The convergence modestly increases in both simulations near day 3 when deep convection begins to occur throughout a large portion of the domain. Although differences between the divergence tendencies (solid black lines) appear small, they are notable. In particular, the downwelling simulation convergence tendency is also $\sim 40 \%$ greater than that of the control simulation during the first 3 days, a period when deep convection is largely absent. The majority of this increase in the divergence tendency results from the pressure terms (blue line; term vii), primarily the Laplacian of pressure. Convection enhances this tendency after day 3 , indicating that diabatic heating by atmospheric convection reinforces the circulation patterns first established by the SST distribution in both simulations. The pressure terms are largely balanced by the redistribution terms (green lines; terms i, ii, iii, and iv), of which advection (term i) is the leading contributor, and the residual (red lines; term viii). The magnitude of the residual is comparable to other leading terms of the budget and correlates well with the pressure terms in the downwelling simulation. The residual includes the effects of friction, particularly along the surface, horizontal and vertical mixing, and any errors in the calculations of other budget terms.

The forcing of divergence by the SST is calculated using the boundary layer wind equation of $\mathrm{Hsu}$ and $\mathrm{Li}$ [2012, their Eq. (5)]. We simplify the wind equation by neglecting the Coriolis, friction, and top of boundary layer forcing terms in order to isolate and analyze the effect of the SST on the boundary layer divergence tendency. Unlike Eq. (5) of Hsu and Li (2012), we assume that the atmosphere is not in a steady state. The vertically integrated divergence tendency may then be expressed as

$$
\left[\frac{\partial \delta}{\partial t}\right]=\left[\frac{R}{2} \frac{\left(p_{s}-p_{e}\right)}{p_{e}} \nabla^{2} \mathrm{SST}\right]
$$

where $R$ is the gas constant for dry air, $p_{s}$ is the surface pressure $(1010 \mathrm{hPa})$, and $p_{e}$ is the pressure of the boundary layer top $(980 \mathrm{hPa})$. Using this calculation, the forcing of convergence by SST (short-dashed black line 

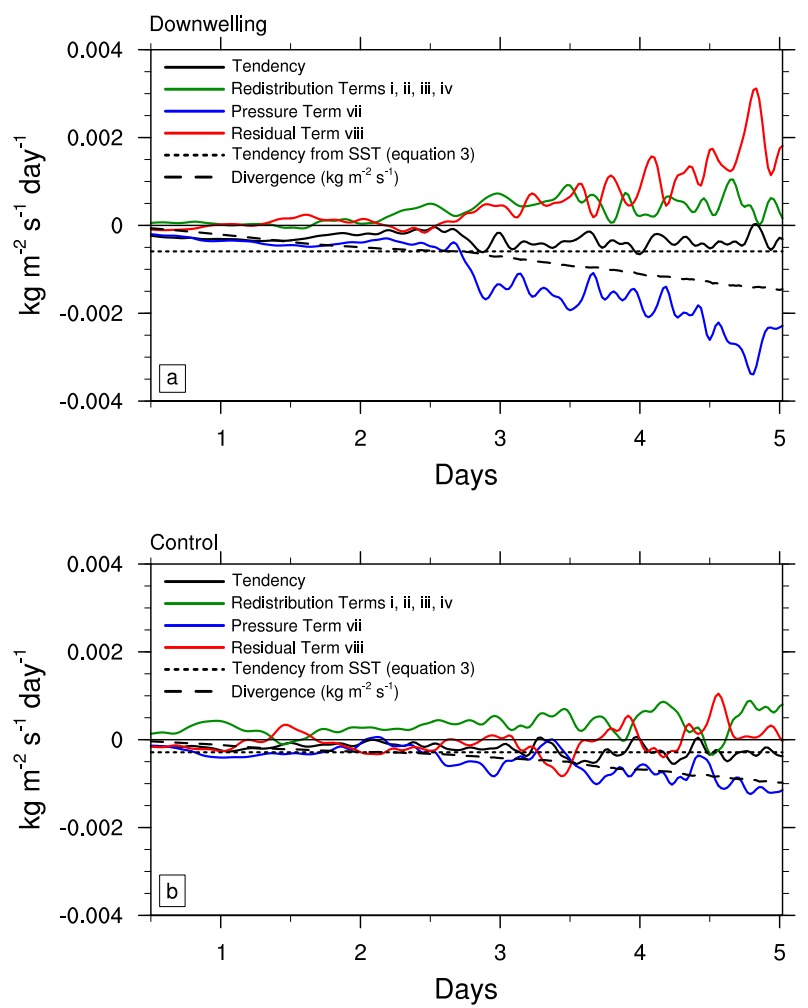

FIG. 6. The divergence tendency terms $\left(\mathrm{kg} \mathrm{m}^{-2} \mathrm{~s}^{-1} \mathrm{day}^{-1}\right)$ averaged meridionally and from 625 to $6255 \mathrm{~km}$ in the zonal direction and vertically integrated from the surface to $270 \mathrm{~m}$ for the (a) downwelling and (b) control simulations. Vertically integrated divergence (long dashed black line; $\mathrm{kg} \mathrm{m}^{-2} \mathrm{~s}^{-1}$ ) is also shown.

in Fig. 6) is approximately twice as strong in the downwelling simulation as the control simulation.

This analysis suggests that prior to deep convection, pressure variations in the downwelling simulation resulting from the SST distribution generate a broad region of convergence at low levels in the model interior, wherein convection organizes on the shoulder of the ascending branch of the overturning circulation near $400 \mathrm{~km}$ (see Fig. 4). In the control simulation, similar processes are operating but are muted when compared to the downwelling simulation. The precipitation maximum in the control occurs near the center of the model domain. This corresponds to the region of maximum static instability, associated with the SST maximum, and convergence forcing by the SST profile. Outward of $625 \mathrm{~km}$, a similar but opposite effect is observed wherein the SST pattern drives low-level divergence (budget terms not shown), thus forming a complete circuit for the solenoidal circulation. This pattern is subsequently strengthened as the descending branch of the circulation intensifies with the formation of deep convection inward of $625 \mathrm{~km}$. Details of the differing rainfall organization patterns between the downwelling and control simulations are examined next.

\section{b. Convective organization}

Divergence is averaged from the surface to $270 \mathrm{~m}$ for the downwelling simulation for days $1,3,5$, and 7 to show finer details of the low-level divergence field in Fig. 7. The meridionally averaged divergence is shown below each panel in green. The low-level atmosphere is, on average, weakly convergent over the model interior during day 1 of the simulation (Fig. 7a), as the boundary layer adjusts to the SST pattern. On day 3 (Fig. 7b), weak convergence persists, and zonally oriented linear couplets of divergence and convergence are present in the regions of strongest SST gradient (SST shown at the bottom of each panel in black), between 250 and $750 \mathrm{~km}$. These initiate as horizontal convective rolls that later develop into rows of shallow cumulus clouds, sometimes referred to as cloud streets (e.g., Malkus and Riehl 1964). On day 5 (Fig. 7c), the horizontal convective rolls intensify and are much better organized with greater meridional spacing characteristic of deeper convective rolls (e.g., Weckwerth et al. 1997). Upward vertical velocities within the rolls are confined below depths of $1 \mathrm{~km}$.

The rolls are joined to meridionally oriented narrow bands of convergence located near $375 \mathrm{~km}$. The meridional bands represent highly organized convective features that transition from shallow convection on day 3 to deep and stratiform convection on day 5 (figure not shown). Discrete open convective cells are present in much of the interior of the domain with divergent downdrafts and convergence along the perimeter of the outflow. On day 7 (Fig. 7d), the horizontal convective rolls have weakened, and convergence is increasingly concentrated along a meridional axis with weak divergence in surrounding regions. The patterns of low-level convergence in the downwelling simulation may be divided into several categories: (i) zonally oriented low-level rolls near regions of strongest SST gradient, (ii) discrete cold pools over the warmest SST, and (iii) meridionally oriented linear features situated by the warm shoulders of the SST gradient maxima.

Figure 8 shows the daily averaged divergence for the control simulation. Like the downwelling simulation, weak convergence occurs, on average, over the model interior on day 1 (Fig. 8a), and horizontal convective rolls begin to organize on day 3 (Fig. $8 \mathrm{~b}$ ). The divergence patterns have greater zonal extent in the control simulation than the downwelling simulation, perhaps owing to the greater static instability there associated with the warmer SSTs. On day 5 (Fig. 8c), horizontal convective 

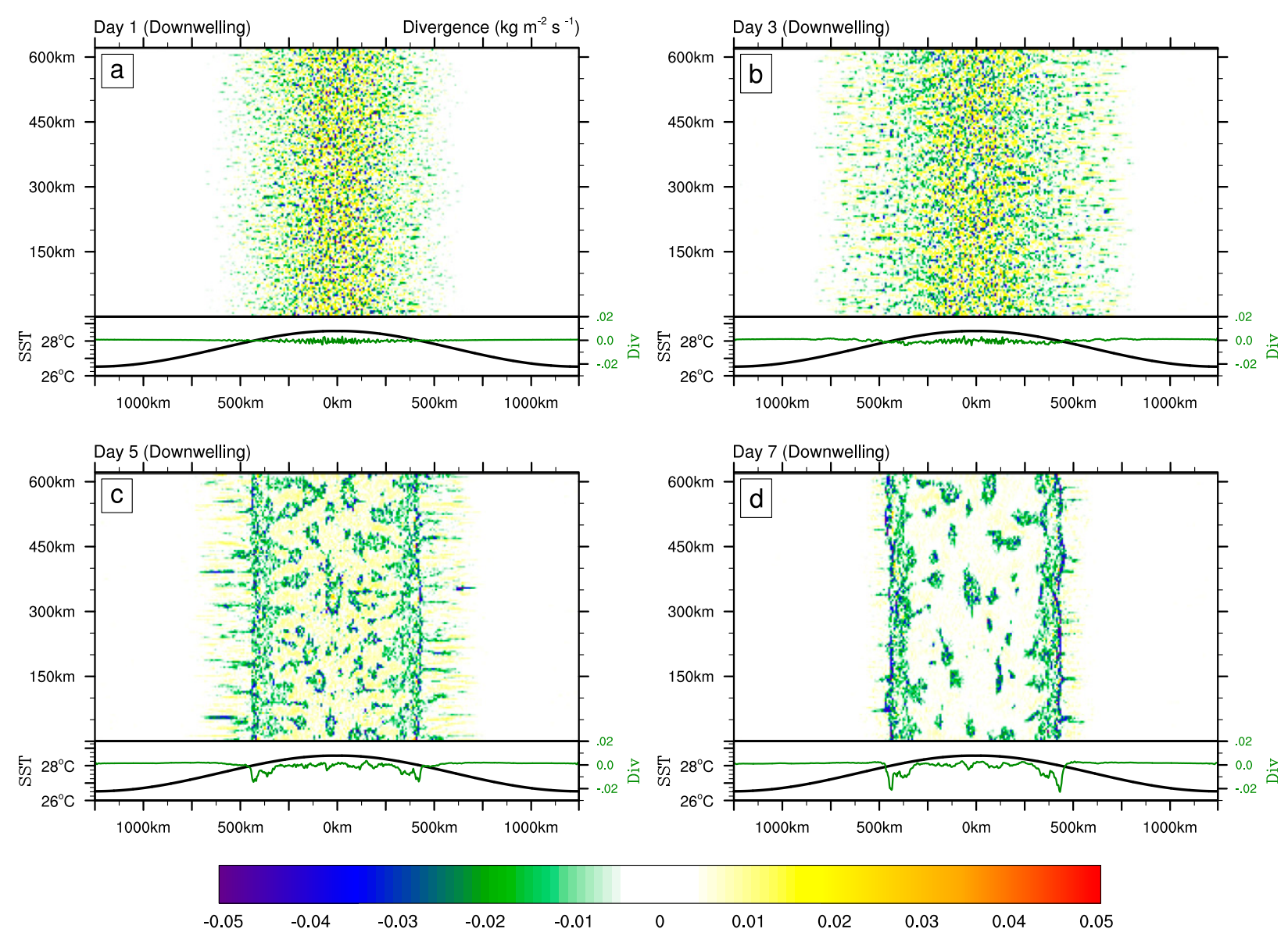

FIG. 7. Daily averaged divergence $\left(\mathrm{kg} \mathrm{m}^{-2} \mathrm{~s}^{-1}\right)$ maps integrated from the surface to $270 \mathrm{~m}$ are shown for (a) day 1, (b) day 3, (c) day 5 , and (d) day 7 of the downwelling simulation. The SST profile (black) and meridionally averaged divergence (green) are shown below each panel.

rolls are joined to open cellular convection near the warmest SST, both of which are associated with deep atmospheric convection. The rolls gradually retreat toward the middle of the domain and further intensify by day 7 (Fig. 8d). Convergence in the control simulation is not organized along distinct meridional axes, as observed in the downwelling simulation, suggesting that the enhanced SST gradient in the downwelling simulation is responsible for the higher degree of convective organization. This might seem surprising given the increased static instability present in the control simulation owing to the warmer SST throughout the domain (see Fig. 3). The role of SST gradients versus absolute SST in determining patterns of convective organization are discussed next.

The analysis of two additional CM1 simulations help to resolve the relative roles of SST magnitude versus SST distribution to patterns of convergence. The first of these utilizes the SST gradient of the control simulation but the same (cooler) domain-averaged SST of the downwelling simulation. With this bottom boundary forcing, precipitating convection is delayed by 1 day compared to the control simulation, indicating that the simulation with the higher mean SST (i.e., control) has a lower static stability and faster onset of precipitation (Fig. 9). However, the downwelling simulation has a lower domain-averaged SST (and thus increased initial static stability) compared to the control simulation but more rapid convective organization than the control simulation because of the stronger SST gradient. This result reinforces the important role of solenoidal circulations generated by large-scale SST gradients for destabilizing the atmosphere of the western Indian Ocean. A second simulation using the domain-averaged SST of the downwelling simulation and no SST gradient resulted in a slower and more disordered convective evolution compared to the downwelling simulation (Fig. 9). Convection required twice as much time to initiate, did not display organized linear convective features, and only produced small amounts of rainfall. 

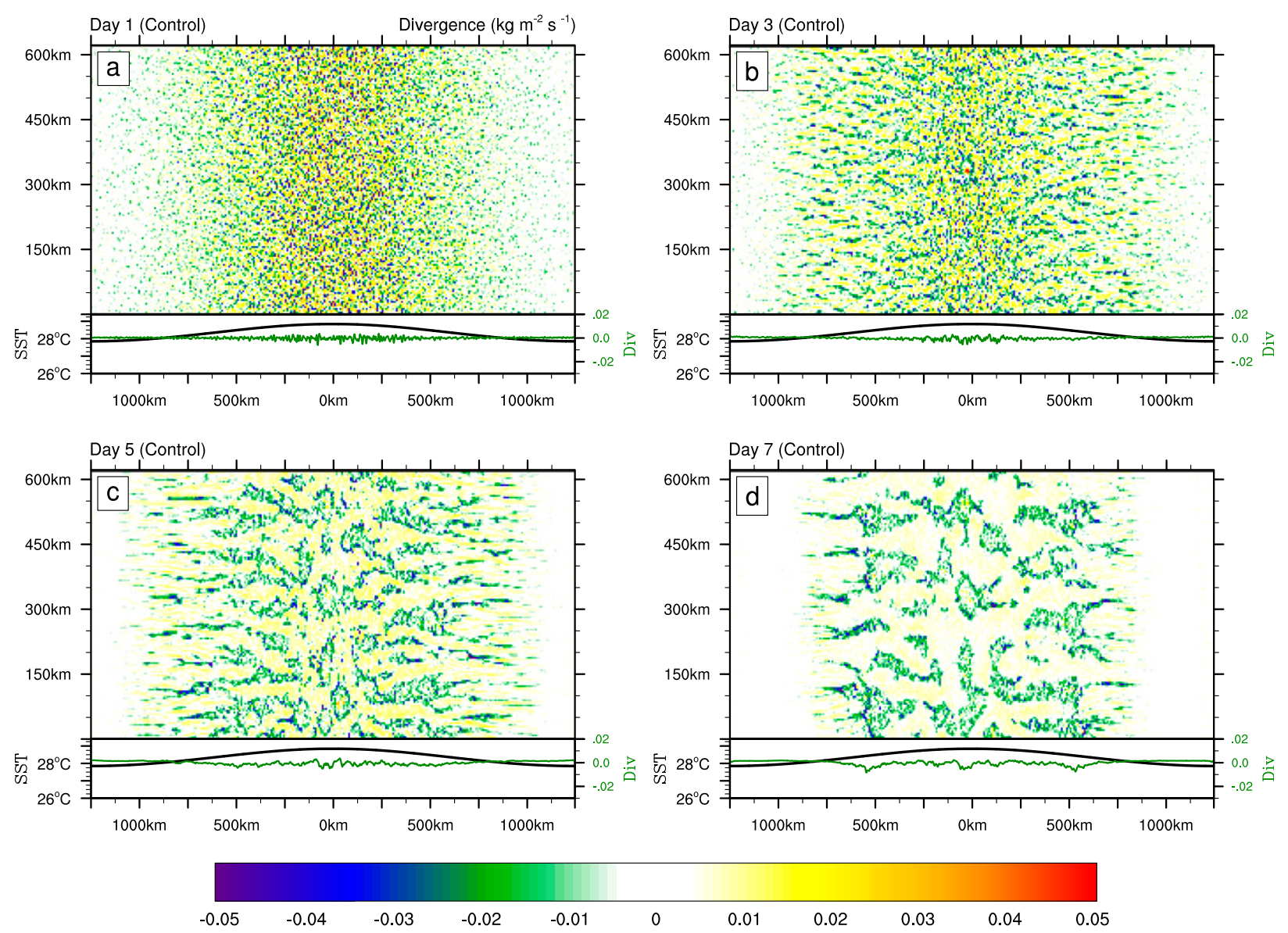

FIG. 8. Daily averaged divergence $\left(\mathrm{kg} \mathrm{m}^{-2} \mathrm{~s}^{-1}\right)$ maps integrated from the surface to $270 \mathrm{~m}$ are shown for (a) day 1 , (b) day 3, (c) day 5, and (d) day 7 of the control simulation. The SST profile (black) and meridionally averaged divergence (green) are shown below each panel.

The results of the additional simulations suggest that strengthening the SST gradient, in addition to organizing convection upscale, accelerates convective initiation in the western Indian Ocean even when hindered by slightly weaker initial static instability.

To ensure that the development and organization of convection are not simply an artifact of the idealized sinusoidal SST shape, simulations were repeated with zonally open boundary conditions and hyperbolic SST shapes. These are referred to as the downwelling narrow-channel and control narrow-channel simulations (see Fig. 3b). Figure 10 shows the divergence patterns for days 1,3,5, and 7 of the downwelling narrow-channel simulation. The general evolution of the divergence patterns is similar, with a meridional convergence band developing by day 5 and evidence of zonally oriented rolls over the region of strongest SST gradient $(2500 \mathrm{~km})$. In the control narrow-channel simulation (Fig. 11), divergence patterns are much more discretized, organized by convective outflow patterns over the warm SST and horizontal convective rolls over the SST gradient maximum, with no significant meridional organization of convection. The consistent patterns of convective organization in the different domains gives confidence to the independence of the results to the specific idealized SST shape. The

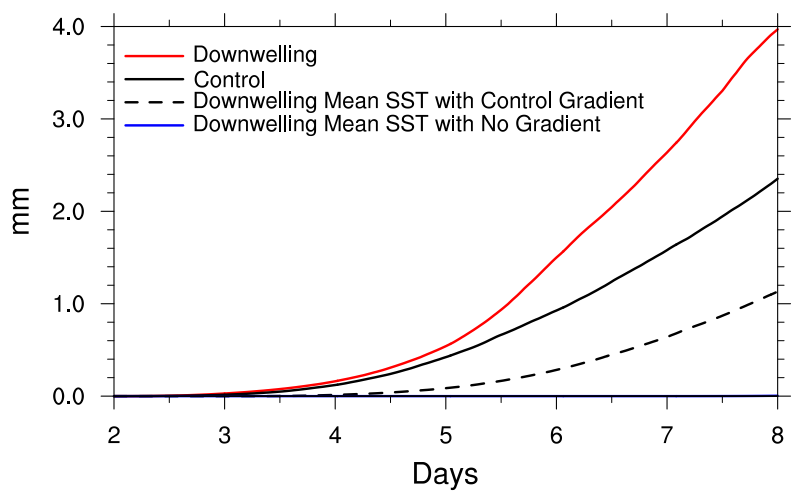

FIG. 9. Domain-averaged accumulated precipitation $(\mathrm{mm})$ is shown for the downwelling (solid red), control (solid black), downwelling mean SST with a gradient of the control (dashed black), and no gradient (solid blue) simulations for days 2-8. 

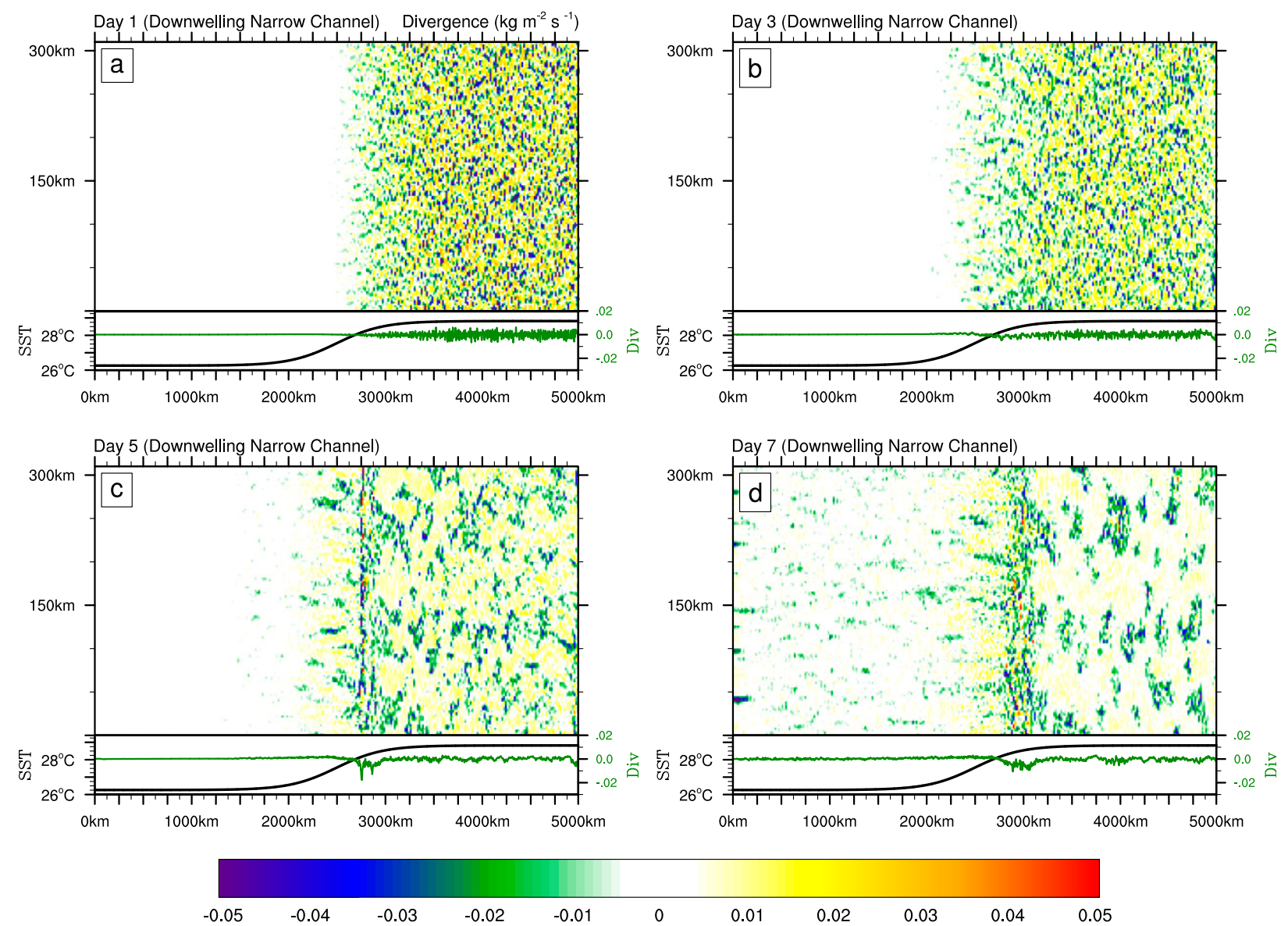

FIG. 10. Daily averaged divergence $\left(\mathrm{kg} \mathrm{m}^{-2} \mathrm{~s}^{-1}\right)$ maps integrated from the surface to $270 \mathrm{~m}$ are shown for (a) day 1, (b) day 3, (c) day 5, and (d) day 7 of the downwelling simulation. The SST profile (black) and meridionally averaged divergence (green) are shown below each panel.

similarity of conclusions drawn by comparing pairs of simulations with the same domain structure give us confidence that the large differences in the organization of convection between our downwelling and control simulations with the doubly periodic domain are not an artifact of the idealized domain itself.

The organization of convergence into meridional strips in the downwelling simulation corresponds to maxima of surface wind speed, surface vapor flux, lowlevel precipitable water (LPW), and rain (Fig. 12). The daily and meridionally averaged surface vapor flux and $10-\mathrm{m}$ wind speed for days 1,3 , and 5 are shown in Figs. 12a and 12c. Line thickness increases with increasing time (i.e., day 5 is thicker than day 3 , and day 3 is thicker than day 1). On day 1 , the surface vapor fluxes in the respective simulations are similar in magnitude because of increased surface wind speed that compensates for the reduced surface temperature in the downwelling simulation (Fig. 12a). On day 3, the surface wind speed in the downwelling simulation maximizes near
$500 \mathrm{~km}$, with surface vapor fluxes maximizing slightly inward of the wind maxima in regions of warmer SSTs. From day 1 to day 3, the wind speed maxima increase by $1 \mathrm{~m} \mathrm{~s}^{-1}$ and the surface vapor flux maxima by $0.5 \mathrm{~mm} \mathrm{day}^{-1}$. At the same time in the control simulation, wind speed and surface flux maxima are collocated near $625 \mathrm{~km}$ with wind speed maxima that are approximately half as strong and surface vapor flux maxima are $\sim 20 \%$ less.

On day 5, the downwelling simulation wind and surface vapor flux maxima have increased to $2.5 \mathrm{~m} \mathrm{~s}^{-1}$ and $1.7 \mathrm{~mm} \mathrm{day}^{-1}$ and are located at $500 \mathrm{~km}$. In the control simulation, wind and surface vapor flux maxima have increased to $1.7 \mathrm{~m} \mathrm{~s}^{-1}$ and $1.4 \mathrm{~mm} \mathrm{day}^{-1}$. Interestingly, maxima in the control simulation have shifted outward such that they are located at $700 \mathrm{~km}$. In the downwelling simulation, maxima of LPW (Fig. 12b) shift inward with increasing time, near the maxima of surface vapor flux and wind speed. The rain on day 5 (Fig. 12d) is maximized near $375 \mathrm{~km}$ in the downwelling simulation and $0 \mathrm{~km}$ in the control simulation. In the control simulation, 

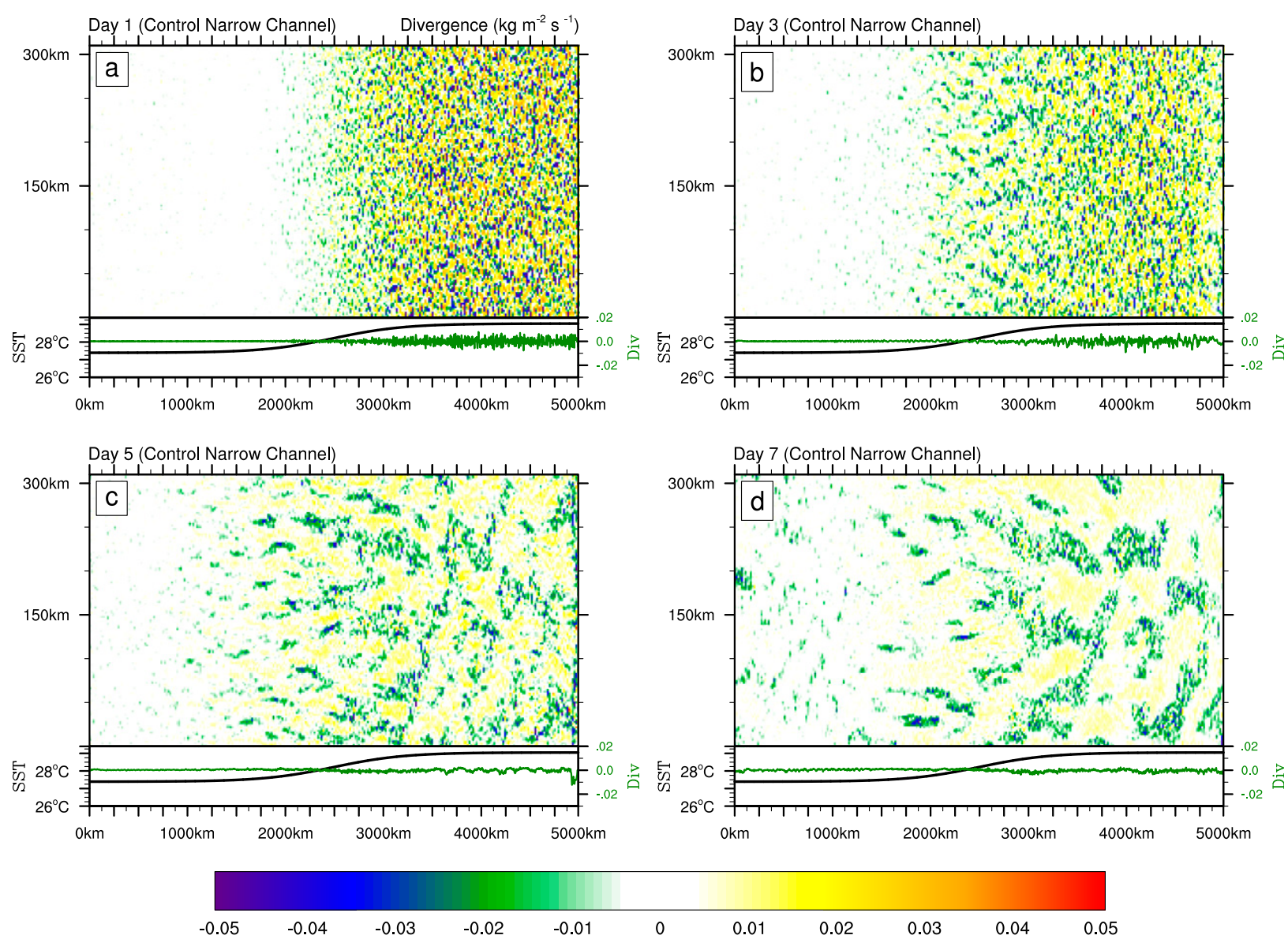

FIG. 11. Daily averaged divergence $\left(\mathrm{kg} \mathrm{m}^{-2} \mathrm{~s}^{-1}\right)$ maps integrated from the surface to $270 \mathrm{~m}$ are shown for (a) day 1, (b) day 3 , (c) day 5, and (d) day 7 of the control simulation. The SST profile (black) and meridionally averaged divergence (green) are shown below each panel.

rain maximizes near the region of greatest initial static instability and convergence forced by the SST. In the downwelling simulation, rain maximizes near the region of greatest LPW, of which surface vapor flux is the greatest source. The behavior of convection shows much greater sensitivity to the location of maximum surface vapor fluxes in the downwelling simulation versus the control simulation, emphasizing their importance during periods of oceanic downwelling equatorial Rossby waves.

Meridional patterns of wind speed, surface vapor flux, LPW, and precipitation are shown for the narrowchannel simulations in Fig. 13. The wind speed maximizes near the strongest SST gradient. The surface vapor flux maxima are mostly collocated, slightly favoring the interior of the domain in the region where the SST pattern supports large-scale convergence. The growth of surface vapor fluxes and LPW are most notable in the downwelling narrow-channel simulation. The precipitation maxima in the downwelling narrowchannel simulation occurs in a region of enhanced surface vapor flux and boundary layer moisture within the ascending branch of the large-scale overturning circulation. This organization is not present in the control narrow-channel simulation, confirming the tendency for convection to organize upscale in downwelling simulations, regardless of the precise idealized SST shape.

Modest increases in boundary layer moisture and convergence are hypothesized to assist the pronounced organization of convection in the downwelling simulation that is absent in the control simulation. Figure 14 shows the differences in relative humidity between the downwelling and control simulations. On day 1 , relative humidity values located near the surface are 5\%-10\% higher in the downwelling simulation (Fig. 14a). Away from the SST maximum, higher relative humidity values partly result from reduced saturation vapor pressure associated with cooler SST in the downwelling simulation. Yet in the region of background convergence (inside of gray lines) near regions of enhanced surface vapor fluxes, increased relative humidity values are also a result of increased absolute moisture (see Fig. 12b). Gray lines 

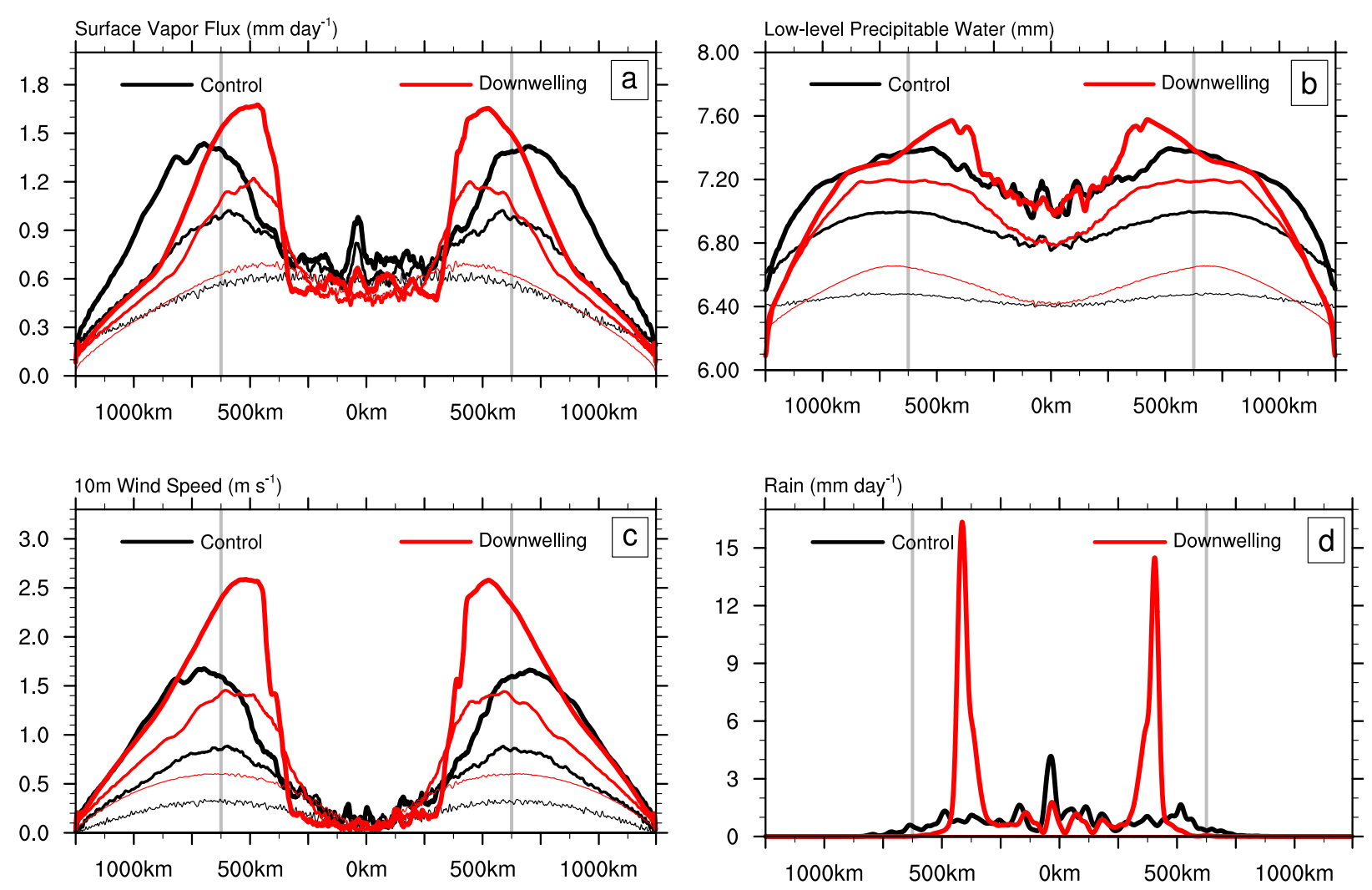

FIG. 12. Meridionally and daily averaged (a) surface vapor flux $\left(\mathrm{mm} \mathrm{day}^{-1}\right),(\mathrm{b})$ low-level precipitable water (mm), (c) 10-m wind speed $\left(\mathrm{m} \mathrm{s}^{-1}\right)$, and $(\mathrm{d})$ rain $\left(\mathrm{mm} \mathrm{day}^{-1}\right)$ are shown for days 1 (thin line), 3 (medium line), and 5 (thick line). Line thickness increases for increasing days. The control simulation is shown in black, and the downwelling simulation is shown in red. Precipitable water is integrated from the surface to $270 \mathrm{~m}$. Only rain for day 5 is shown in (d). Gray lines indicate the location of maximum SST gradient.

distinguish regions of ascending motion within the SSTdriven solenoidal circulation inward of $625 \mathrm{~km}$ from regions of SST-forced descent in outward of $625 \mathrm{~km}$. Enhanced boundary layer moistening is associated with development of shallow convection on day 3 where a relative humidity increase of $5 \%$ in the downwelling simulations occurs near $375 \mathrm{~km}$ at heights of $1-3 \mathrm{~km}$ (Fig. 14b). On day 5 (Fig. 14c), the strongest relative humidity differences are located between heights of 2 and $5 \mathrm{~km}$. On day 7 (Fig. 14d), the availability of boundary layer moisture associated with the downwelling simulation is more supportive of deep convection than the control simulation. Deep convection in the control simulation favors the center of the model domain but is not as well supported by boundary layer moisture as deep convection in the downwelling simulation near $400 \mathrm{~km}$.

\section{Discussion}

The collocation of surface latent heat flux, boundary layer moisture, and wind speed maxima suggest that latent heat fluxes initially forced by the SST gradient are the leading contributor to the organization and intensification of convection in the downwelling versus control simulations. If SST-forced convergence were the dominant mechanism of convective organization, then convection would be expected to favor the region of maximum SST forcing in the center of the domain where the negative Laplacian of SST is a minimum. Instead, convection in the downwelling simulation favors regions in close proximity to the SST gradient maximum. The shift of convection from the region of maximum SST gradient toward the maximum SST results from the downstream advection of moisture, large-scale convergence of moisture toward the model interior, and sensitivity of surface vapor fluxes to warmer SSTs. Convection occurs within the ascending branch of the overturning circulation, such that the SST-forced convergence yields a favorable region for convective intensification and organization. The effect of the SST distribution on the low-level moisture patterns strongly regulates the location, intensity, and organization of convection. 

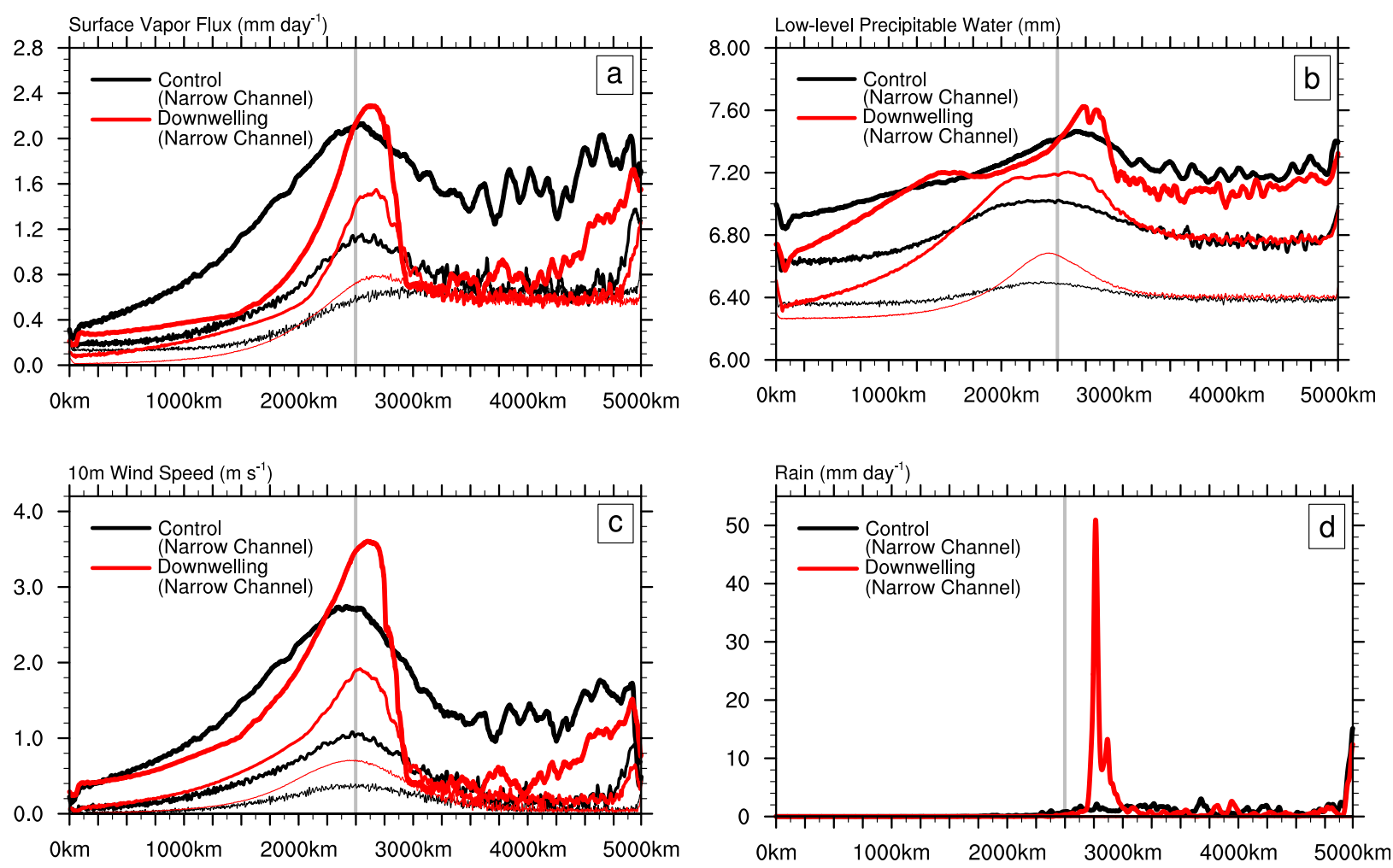

FIG. 13. Meridionally and daily averaged (a) surface vapor flux $\left(\mathrm{mm} \mathrm{day}^{-1}\right)$, (b) low-level precipitable water (mm), (c) 10-m wind speed $\left(\mathrm{m} \mathrm{s}^{-1}\right)$, and $(\mathrm{d})$ rain $\left(\mathrm{mm} \mathrm{day}^{-1}\right)$ are shown for days 1 (thin line), 3 (medium line), and 5 (thick line). Line thickness increases for increasing days. The control narrow-channel simulation is shown in black, and the downwelling narrow-channel simulation is shown in red. Precipitable water is integrated from the surface to $270 \mathrm{~m}$. Only rain for day 5 is shown in (d). Gray lines indicate the location of maximum SST gradient.

In both the downwelling and control simulations, lowlevel convergence and boundary layer humidification precede the formation of clouds. The large-scale moisture and convergence patterns are initially organized into zonally elongated couplets of convergence and divergence along borders of boundary layer rolls. Rowe and Houze (2015) observed similar boundary layer rolls during the transition from suppressed to active phases of the ISO using dual-polarimetric radar during the DYNAMO field campaign in the Indian Ocean. Rolls developed into precipitating clouds that formed cold pools responsible for initiating new cumulus clouds that eventually organized into mesoscale convective systems. Ruppert and Johnson (2015) showed a similar evolution of cloud populations during DYNAMO using in situ observations and MODIS satellite imagery. They observed that mesoscale organization of moisture and a deepening of the boundary layer assist the upscale growth and horizontal coverage of cumulus clouds that are linked to moistening of the free troposphere prior to convectively active ISO phases. Rowe and Houze (2015) hypothesized that the boundary layer rolls organize the initial nonprecipitating cumulus clouds from which the first precipitating features develop, and these lead the transition to the convectively active phase of the ISO. However, an additional sensitivity test in CM1 suggests that horizontal convective rolls are not essential to the development of meridional convective lines in the model. In this simulation, the magnitude of the downwelling SST gradient is doubled. The organization and intensity of convection is similar to that implied by Figs. 7 and 12, but horizontal rolls largely fail to develop.

Critical to the atmospheric response to SST gradients is the growth and organization of boundary layer moisture hypothesized to initiate ISO convection (e.g., Seo and Kumar 2008; Zhao et al. 2013; Li et al. 2015; Mei et al. 2015; Rydbeck et al. 2017). In the downwelling simulation with no background wind, the increase of low-level moisture and its organization is predominantly a result of surface latent heat fluxes. Through examination of the boundary layer moisture budget, horizontal convergence at low levels is largely opposed by the vertical flux of moisture out of the boundary layer, resulting in only minor low-level moistening by vertical advection, the sum of horizontal convergence and vertical moisture flux, during days $0-4$. The latent heat flux 

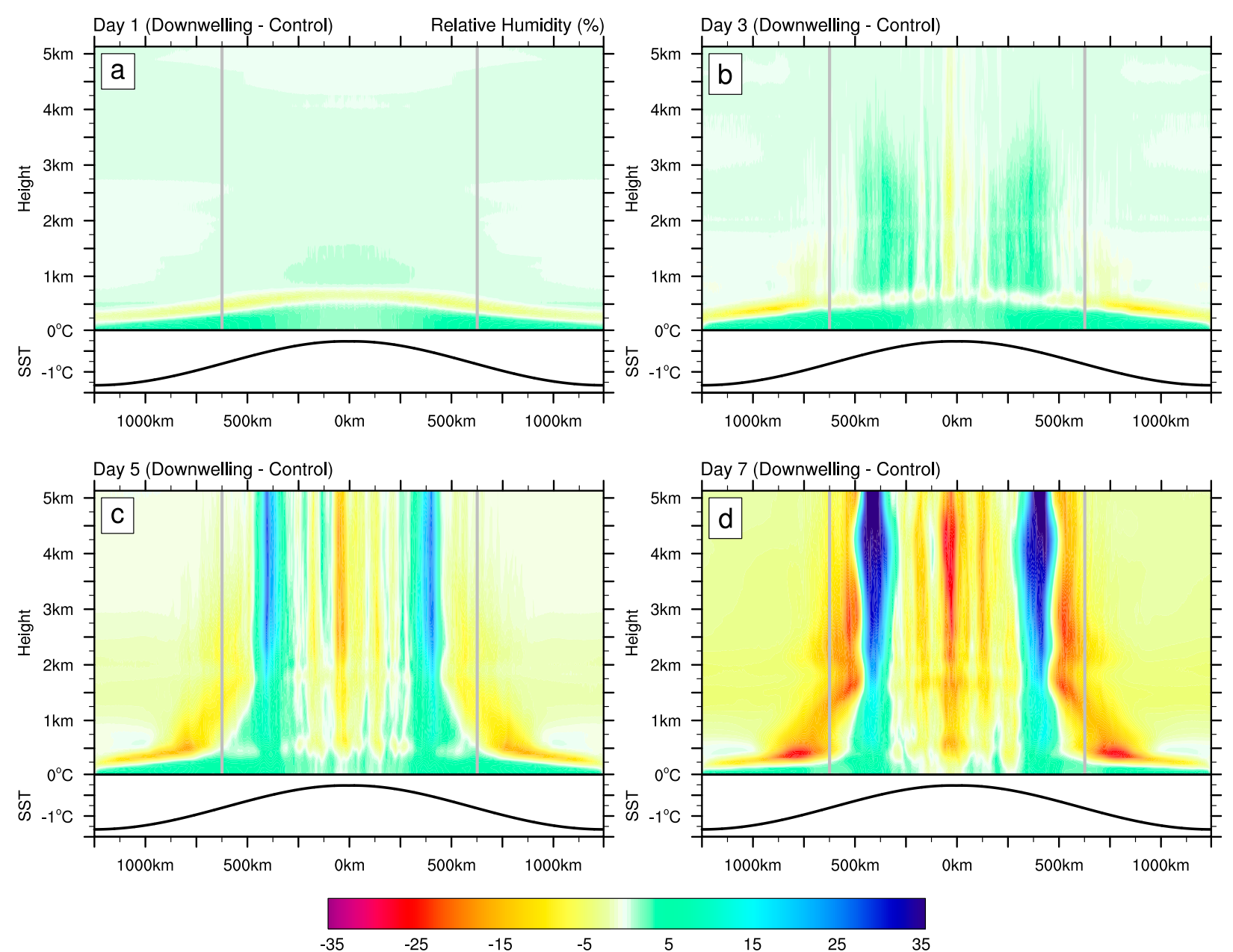

FIG. 14. Meridionally and daily averaged relative humidity differences (downwelling minus control) are shown for (a) day 1, (b) day 3 , (c) day 5, and (d) day 7. Gray lines indicate location of maximum SST gradient. The SST difference between the downwelling and control simulations is shown below each panel.

calculations in CM1 do not account for the additional contribution to the bulk algorithm made by strong westward surface currents of $0.8 \mathrm{~m} \mathrm{~s}^{-1}$ associated with oceanic downwelling equatorial Rossby waves (Rydbeck et al. 2017). Such currents might increase the speed differential at the ocean and atmosphere interface leading to enhanced latent heat fluxes.

An additional simplification of the idealized CM1 simulations is the exclusion of planetary vorticity. While omitted in these simulations, the Coriolis force modulates the low-level divergence tendency [terms $\mathrm{v}$ and vi of Eq. (1)]. Moreover, large-scale planetary waves, such as Rossby and Kelvin waves, generated as a response to tropical convective heating (Gill 1980) are suppressed. Observations have shown that these planetary waves modulate atmospheric moisture within the ISO (e.g., Hendon and Salby 1994; Maloney and Hartmann 1998). Future work with coupled models is required to quantify the full response of convection to oceanic downwelling equatorial Rossby waves.

\section{Conclusions}

The role of oceanic downwelling equatorial Rossby waves in ISO convective onset is investigated using an idealized model. Downwelling equatorial Rossby waves modify the SST distribution in the western Indian Ocean; the most notable change is a strengthening of the horizontal SST gradients. The SST changes are associated with an increase in boundary layer convergence and atmospheric convection in observations and atmospheric reanalysis (Rydbeck and Jensen 2017). Using CM1 with explicit boundary layer physics and convection, simulations are performed with zonal SST distributions representative of periods with and without oceanic downwelling equatorial Rossby waves. The 


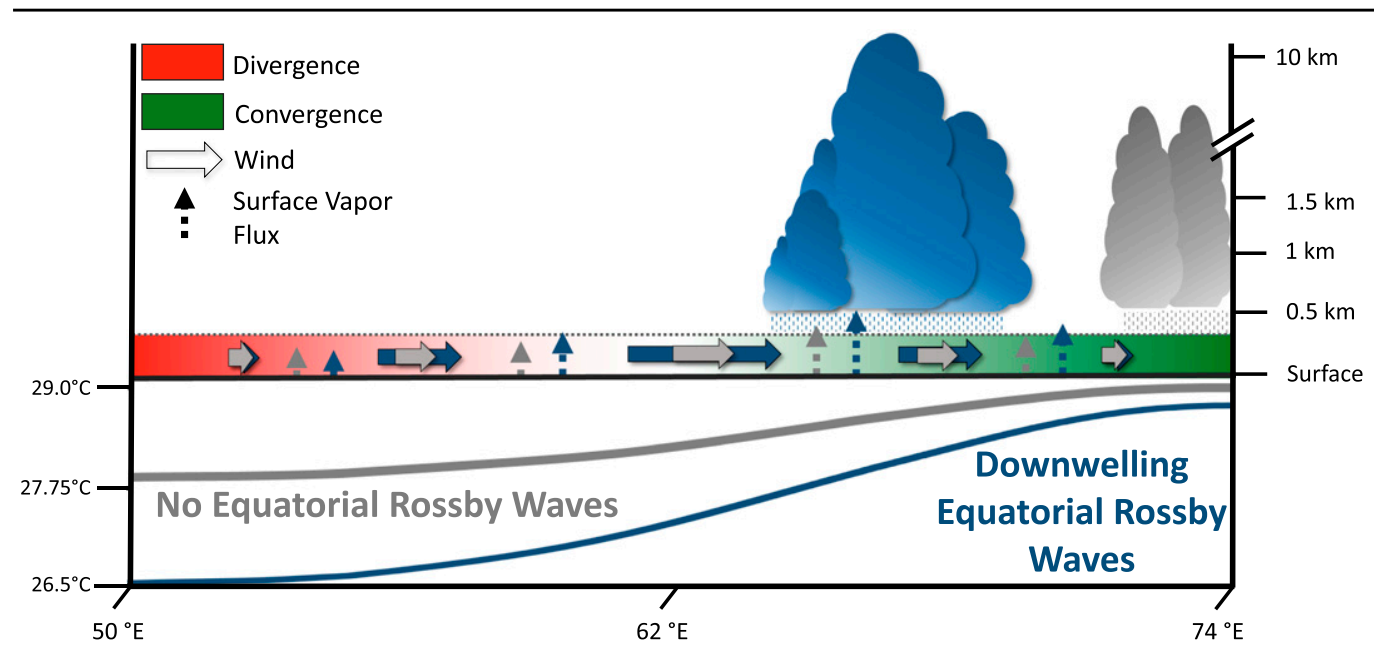

FIG. 15. A schematic of the atmospheric response to SST forcing from downwelling equatorial Rossby waves in the idealized modeling simulations. The SST, winds, divergence, surface vapor fluxes, and convective response are shown. Variables for periods with (without) downwelling equatorial Rossby waves are shown in blue (gray).

former is referred to as the downwelling simulation and the latter as the control simulation. Both are initiated with a composite sounding from reanalysis that corresponds to the transition from suppressed to active intraseasonal convection in the western Indian Ocean. Simulations are performed for 10 days in order to capture the atmospheric adjustment to the imposed SST anomalies.

The downwelling simulation is characterized by rapidly developing and highly organized convection and precipitation. Initially, horizontal convective rolls develop at low levels corresponding to convergence and divergence couplets that are embedded within a large overturning circulation that is thermally forced by the SST distribution. By day 7 of the simulation, maxima of precipitation, moisture, surface vapor flux, precipitable water, and convergence are arranged into narrow meridional bands. The highly organized convection is located in the region of maximum boundary layer moisture produced by enhanced surface vapor fluxes and within the ascending branch of the circulation driven by the SST. The convergence tendency diagnosed from the SST largely agrees with the tendency calculated using the atmospheric pressure field and suggests that SST-driven convergence in the downwelling simulation is $\sim 40 \%$ greater than the control simulation. However, deep convection is not collocated with the greatest SST-forced low-level convergence or warmest SST, except in the control simulation.

Atmospheric deep convection in the control simulation is much less organized than that in the downwelling simulation. The control SST gradient is weak, resulting in weak surface winds and a weak overturning circulation. This combination leads to anemic surface vapor fluxes and low-level precipitable water. Discrete convection occurs close to the warmest SST and is limited by relatively weak boundary layer moisture. Rain peaks at the location of warmest SST, greatest static instability, and greatest SST-forced convergence.

The effect of the SST distribution associated with oceanic downwelling equatorial Rossby waves is summarized in Fig. 15. A comparison of simulations with and without the enhanced SST gradient forced by downwelling Rossby waves indicate a regime shift wherein precipitation relocates from the region of warmest SST and maximum SST-forced convergence, as noted in the control simulations, to regions of enhanced surface latent heat fluxes near the SST gradient maximum. This is consistent with the investigation of Rydbeck and Jensen (2017), where enhanced SST gradient magnitudes associated with oceanic equatorial Rossby waves are associated with a concomitant increase of precipitation (Fig. 11 of their paper). The major hypotheses developed in this study are as follows:

1) Downwelling equatorial Rossby waves steepen the SST gradient in the western Indian Ocean. In response, surface wind speeds, latent heat fluxes, boundary layer precipitable water, and boundary layer convergence increase.

2) Downwelling equatorial Rossby waves modulate atmospheric boundary layer convergence and surface latent heat fluxes. The resulting convective intensification and organization is predominantly a result of enhanced moistening by surface latent heat fluxes that is located in regions of SST-forced convergence. 
The processes listed above are suggested as mechanisms for rapid intraseasonal convective development and organization associated with oceanic downwelling equatorial Rossby waves. These results suggest that, in the absence of other forcing, ISO convective initiation associated with downwelling waves is expected to occur within a zone of warm SSTs near the strongest SST gradient, and not simply over the warmest SST. Our results also suggest that equatorial Rossby wave-related intraseasonal convection is limited to areas where they are impactful to the magnitude of surface latent heat fluxes. The slow transit speed of downwelling equatorial Rossby waves across the Indian Ocean (75-90 days) suggests that predictability of ISO initiation events at lead times of several months is possible.

Acknowledgments. The authors thank four anonymous reviewers and W. Grabowski for comments that greatly improved the manuscript. MRI acknowledges funding from UC Davis. Financial support for AVR is provided by the NRL Karles Fellowship (Grant 73N2P4-08-5) and for TGJ by the U.S. Office of Naval Research PISTON (Grant 73-4347-27-5) and NASCar (Grant 73-4347-34-5) projects.

\section{REFERENCES}

Back, L., and C. Bretherton, 2009: A simple model of climatological rainfall and vertical motion patterns over the tropical oceans. J. Climate, 22, 6477-6497, https://doi.org/10.1175/ 2009JCLI2393.1.

Bretherton, C. S., and A. H. Sobel, 2002: A simple model of a convectively coupled walker circulation using the weak temperature gradient approximation. J. Climate, 15, 2907-2920, https:/doi.org/ 10.1175/1520-0442(2002)015<2907:ASMOAC >2.0.CO;2.

_, P. N. Blossey, and M. E. Peters, 2006: Interpretation of simple and cloud-resolving simulations of moist convection-radiation interaction with a mock-Walker circulation. Theor. Comput. Fluid Dyn., 20, 421-442, https://doi.org/10.1007/s00162-0060029-7.

Bryan, G. H., and J. M. Fritsch, 2002: A benchmark simulation for moist nonhydrostatic numerical models. Mon. Wea. Rev., 130, 2917-2928, https://doi.org/10.1175/1520-0493(2002)130<2917: ABSFMN $>2.0 . C O ; 2$.

Carbone, R. E., and Y. Li, 2015: Tropical oceanic rainfall and sea surface temperature structure: Parsing causation from correlation in the MJO. J. Atmos. Sci., 72, 2703-2718, https:// doi.org/10.1175/JAS-D-14-0226.1.

Chen, S. S., and Coauthors, 2016: Aircraft observations of dry air, the ITCZ, convective cloud systems, and cold pools in MJO during DYNAMO. Bull. Amer. Meteor. Soc., 97, 405-423, https://doi.org/10.1175/BAMS-D-13-00196.1.

Deardorff, J. W., 1980: Stratocumulus-capped mixed layers derived from a three-dimensional model. Bound.-Layer Meteor., 18, 495-527, https://doi.org/10.1007/BF00119502.

Gill, A. E., 1980: Some simple solutions for heat-induced tropical circulation. Quart. J. Roy. Meteor. Soc., 106, 447-462, https:// doi.org/10.1002/qj.49710644905.
Grabowski, W. W., J.-I. Yano, and M. W. Moncrieff, 2000: Cloud resolving modeling of tropical circulations driven by largescale SST gradients. J. Atmos. Sci., 57, 2022-2040, https:// doi.org/10.1175/1520-0469(2000)057<2022:CRMOTC $>$ 2.0.CO;2.

Hendon, H., and M. Salby, 1994: The life cycle of the MaddenJulian oscillation. J. Atmos. Sci., 51, 2225-2237, https://doi.org/ 10.1175/1520-0469(1994)051<2225:TLCOTM >2.0.CO;2.

Hsu, P. C., and T. Li, 2012: Role of the boundary layer moisture asymmetry in causing the eastward propagation of the Madden-Julian oscillation. J. Climate, 25, 4914-4931, https:// doi.org/10.1175/JCLI-D-11-00310.1.

Johnson, R. H., and P. E. Ciesielski, 2017: Multiscale variability of the atmospheric boundary layer during DYNAMO. J. Atmos. Sci., 74, 4003-4021, https://doi.org/10.1175/JASD-17-0182.1.

Klemp, J. B., W. C. Skamarock, and J. Dudhia, 2007: Conservative split-explicit time integration methods for the compressible nonhydrostatic equations. Mon. Wea. Rev., 135, 2897-2913, https://doi.org/10.1175/MWR3440.1.

Kuang, Z., 2012: Weakly forced mock Walker cells. J. Atmos. Sci., 69, 2759-2786, https://doi.org/10.1175/JAS-D-11-0307.1.

Li, T., C. Zhao, P. Hsu, and T. Nasuno, 2015: MJO initiation processes over the tropical Indian Ocean during DYNAMO/ CINDY2011. J. Climate, 28, 2121-2135, https://doi.org/10.1175/ JCLI-D-14-00328.1.

Li, Y., and R. E. Carbone, 2012: Excitation of rainfall over the tropical western Pacific. J. Atmos. Sci., 69, 2983-2994, https:// doi.org/10.1175/JAS-D-11-0245.1.

Lindzen, R., and S. Nigam, 1987: On the role of sea surface temperature gradients in forcing low-level winds and convergence in the tropics. J. Atmos. Sci., 44, 2418-2436, https://doi.org/ 10.1175/1520-0469(1987)044<2418:OTROSS >2.0.CO;2.

Madden, R. A., and P. R. Julian, 1971: Detection of a 40-50 day oscillation in the zonal wind in the tropical Pacific. J. Atmos. Sci., 28, 702-708, https://doi.org/10.1175/1520-0469(1971) 028<0702:DOADOI $>2.0 . \mathrm{CO} ; 2$.

Malkus, J. S., 1957: Trade cumulus cloud groups: Some observations suggesting a mechanism of their origin. Tellus, 9, 33-44, https://doi.org/10.3402/tellusa.v9i1.9071.

- and H. Riehl, 1964: Cloud structure and distributions over the tropical Pacific Ocean. Tellus, 16, 275-287, https://doi.org/ 10.1111/j.2153-3490.1964.tb00167.x.

Maloney, E., and D. Hartmann, 1998: Frictional moisture convergence in a composite life cycle of the Madden-Julian oscillation. J. Climate, 11, 2387-2403, https://doi.org/10.1175/1520-0442(1998) $011<2387$ :FMCIAC $>2.0$. CO; 2 .

Mei, S., T. Li, and W. Chen, 2015: Three-type MJO initiation processes over the western equatorial Indian Ocean. Adv. Atmos. Sci., 32, 1208-1216, https://doi.org/10.1007/ s00376-015-4201-0.

Morrison, H., J. A. Curry, M. D. Shupe, and P. Zuidema, 2005: A new double-moment microphysics parameterization for application in cloud and climate models. Part II: Single-column modeling of Arctic clouds. J. Atmos. Sci., 62, 1678-1693, https://doi.org/10.1175/JAS3447.1.

—, G. Thompson, and V. Tatarskii, 2009: Impact of cloud microphysics on the development of trailing stratiform precipitation in a simulated squall line: Comparison of one- and two-moment schemes. Mon. Wea. Rev., 137, 991-1007, https://doi.org/10.1175/ 2008MWR2556.1.

Moum, J. N., and Coauthors, 2014: Air-sea interactions from westerly wind bursts during the November 2011 MJO in the 
Indian Ocean. Bull. Amer. Meteor. Soc., 95, 1185-1199, https:// doi.org/10.1175/BAMS-D-12-00225.1.

, K. Pujiana, R. C. Lien, and W. D. Smyth, 2016: Ocean feedback to pulses of the Madden-Julian oscillation in the equatorial Indian Ocean. Nat. Commun., 7, 13203, https:// doi.org/10.1038/ncomms13203.

Neelin, J. D., I. M. Held, and K. H. Cook, 1987: Evaporation-wind feedback and low-frequency variability in the tropical atmosphere. J. Atmos. Sci., 44, 2341-2348, https://doi.org/10.1175/ 1520-0469(1987)044<2341:EWFALF $>2.0 . C O ; 2$.

Rowe, A. K., and R. A. Houze, 2015: Cloud organization and growth during the transition from suppressed to active MJO conditions. J. Geophys. Res. Atmos., 120, 10 324-10 350, https://doi.org/10.1002/2014JD022948.

Ruppert, J. H., 2016: Diurnal timescale feedbacks in the tropical cumulus regime. J. Adv. Model. Earth Syst., 8, 1483-1500, https://doi.org/10.1002/2016MS000713.

—_, and R. H. Johnson, 2015: Diurnally modulated cumulus moistening in the preonset stage of the Madden-Julian oscillation during DYNAMO. J. Atmos. Sci., 72, 16221647, https://doi.org/10.1175/JAS-D-14-0218.1.

- , and — 2016: On the cumulus diurnal cycle over the tropical warm pool. J. Adv. Model. Earth Syst., 8, 669-690, https:// doi.org/10.1002/2015MS000610.

Rydbeck, A. V., and T. G. Jensen, 2017: Oceanic impetus for convective onset of the Madden-Julian oscillation in the western Indian Ocean. J. Climate, 30, 4299-4316, https:// doi.org/10.1175/JCLI-D-16-0595.1.

, - - and E. S. Nyadjro, 2017: Intraseasonal sea surface warming in the western Indian Ocean by oceanic equatorial Rossby waves. Geophys. Res. Lett., 44, 4224-4232, https:// doi.org/10.1002/2017GL073331.

Seo, K. H., and A. Kumar, 2008: The onset and life span of the Madden-Julian oscillation. Theor. Appl. Climatol., 94, 13-24, https://doi.org/10.1007/s00704-007-0340-2.
Sherman, L., 1952: On the scalar-vorticity and horizontal-divergence equations. J. Meteor., 9, 359-366, https://doi.org/10.1175/15200469(1952)009<0359:OTSVAH > 2.0.CO;2.

Stevens, D. E., 1979: Vorticity, momentum and divergence budgets of synoptic-scale wave disturbances in the tropical eastern Atlantic. Mon. Wea. Rev., 107, 535-550, https://doi.org/10.1175/ 1520-0493(1979)107<0535:VMADBO >2.0.CO;2.

Webber, B. G., A. J. Matthews, and K. J. Heywood, 2010: A dynamical ocean feedback mechanism for the MaddenJulian oscillation. Quart. J. Roy. Meteor. Soc., 136, 740-754, https://doi.org/10.1002/qj.604.

,,,--- and D. P. Stevens, 2012a: Ocean Rossby waves as a triggering mechanism for primary Madden-Julian events. Quart. J. Roy. Meteor. Soc., 138, 514-527, https:// doi.org/10.1002/qj.936.

- D. P. Stevens, A. J. Matthews, and K. J. Heywood, 2012b: Dynamical ocean forcing of the Madden-Julian oscillation at lead times of up to five months. J. Climate, 25, 2824-2842, https://doi.org/10.1175/JCLI-D-11-00268.1.

Weckwerth, T. M., J. W. Wilson, R. M. Wakimoto, and N. A. Crook, 1997: Horizontal convective rolls: Determining the environmental conditions supporting their existence and characteristics. Mon. Wea. Rev., 125, 505-526, https://doi.org/ 10.1175/1520-0493(1997)125<0505:HCRDTE > 2.0.CO;2.

Wicker, L. J., and W. C. Skamarock, 2002: Time-splitting methods for elastic models using forward time schemes. Mon. Wea. Rev., 130, 2088-2097, https://doi.org/10.1175/1520-0493(2002) $130<2088$ :TSMFEM $>2.0$. CO;2.

Wilhelmson, R. B., and C.-S. Chen, 1982: A simulation of the development of successive cells along a cold outflow boundary. J. Atmos. Sci., 39, 1466-1483, https://doi.org/10.1175/ 1520-0469(1982)039<1466:ASOTDO > 2.0.CO;2.

Zhao, C., T. Li, and T. Zhou, 2013: Precursor signals and processes associated with MJO initiation over the tropical Indian Ocean. J. Climate, 26, 291-307, https://doi.org/10.1175/JCLI-D-12-00113.1. 